\title{
Affective Negotiation Support Systems
}

\author{
Joost Broekens $^{\mathrm{a}^{*}}$, Catholijn M. Jonker ${ }^{\mathrm{a}}$ and John-Jules Ch. Meyer ${ }^{\mathrm{b}}$ \\ ${ }^{a}$ MMI, TU Delft, Mekelweg 4, 2628 CD, Delft, The Netherlands \\ ${ }^{\mathrm{b}}$ Computer Science, Utrecht University, Padualaan 14, 3584CH, Utrecht, The Netherlands
}

\begin{abstract}
Negotiation is a process in which two or more parties aim to reach a joint agreement. As such negotiation involves rational decision making about options and issues. However, negotiation also involves social interaction and dilemmas as well as personal preferences and opinions. Negotiation is a multifaceted process in which affect plays a critical role, a role confirmed in recent empirical studies. In this position paper we first argue that affect is an important issue to consider when developing a negotiation support system. We do so by giving a strategic overview of some of the most important findings in the affect-cognition and affect-negotiation literature. Second, we show in a structured manner during which phases in the negotiation process what emotion-related concepts play a major role, as well as discuss more concrete affect-related support functions an affective negotiation support system could offer. Third, we analyze the feasibility of these functions by reviewing currently available affective computing technologies, such as affect measurement, emotion modeling, emotion expression, emotional reasoning, and emotional agents.
\end{abstract}

Keywords: Affect, Negotiation, Negotiation Support Systems, Affective Computing, Review

\section{Introduction}

Negotiation is a process in which two or more parties aim to reach a joint agreement regarding an exchange of goods and services. As such, negotiation involves rational decision making about options and issues. For example, given the choice between two car deals, one has to decide about price, model, color, warrantee, etc. Listing and weighing these car-related issues can be seen as a rational process for coming up with a combined value for each option. Negotiation experts $[55,144]$ emphasize that negotiation is not just about money and exchange of property, but also about relationships, awareness of all issues (domain model), personal preferences (user and opponent model), making sure you have a good alternative (if no deal is reached), and reflection on your performance. So, not only objective aspects such as money, color and brand are important, but also more subjective issues such as, do I want to keep this car dealer, will I see this person again, did I explore enough alternative cars, how much do I like this car, do I want to be seen in this model. In addition, a by now considerable body of research has shown that emotions influence the negotiation outcome. For example, the best negotiation outcomes are reached when people manage to create and maintain a positive and relaxed atmosphere, see e.g., [27, 105, 144]. Negotiating is an emotional process, certainly for the novice negotiator [147]. The more that depends on the outcome of the negotiation, the more intense the emotions. Negative feelings such as not being in control of the situation, not knowing what to expect, and fearing to underperform inhibit the exchange of information about underlying concerns, whereas in a relaxed atmosphere the additional information broadens the scope of the negotiation [56, 146]. In fact, a bad atmosphere and a lack of information are structural barriers to agreement [99]. Furthermore, human negotiators make mental errors some of which are related to emotions, such as biased perception, irrational expectations, overconfidence, and unchecked emotions [99].

Interestingly, recent research shows that the display of negative emotions such as anger can in some cases enhance the negotiation outcome for the person showing the negative emotion [138]. However, this beneficial effect is dependent on the strength of the alternatives of the opponent $[45,138]$. This indicates that both positive emotions and negative emotions

*Corresponding author. E-mail: joost.broekens@gmail.com. 
can be useful and detrimental to the negotiation process. In fact, the relation between emotion and negotiation is complex [7, 47]. In this article we first review and structure the relation between emotion and negotiation.

Two areas of research related to negotiation software can be distinguished: negotiation support systems (NSS) and automated negotiating agents (ANA). Whereas the focus of the former type of software is on enabling a user to negotiate by means of structuring the process and possibly by offering analysis support, in essence a special purpose decision support system, the latter type of software is aimed at automating (parts of a) negotiation completely [73]. Up until now, a negotiation support system (NSS) supports negotiators with the rational part of the negotiation process such as exploration of issues, identification of alternatives and calculating bids [73]. As emotions play such an important role in the negotiation process, in this article we argue that negotiation support systems should help negotiators cope with the interplay between emotion and the negotiation process. We show in what ways such a system could help, and we discuss the feasibility of these ideas in relation to current affective computing techniques. In this article we do not present a working system or evaluations thereof. We argue, based on the affect negotiation literature, for the inclusion of affectrelated functionality in such systems as well as show what kind of functions affect could have in such systems. Secondly, we show that some - but definitely not all - of these functions are feasible in the near future.

The type of Affective Negotiation Support System we envision is an ambient intelligent device. A typical user would use the Affective NSS on a mobile device (smart phone, small laptop). It uses lowinvasive emotion measurement technology [150] to assess the user's emotional state and it uses artificial intelligence techniques to proactively assist the user in making negotiation-related decisions. So, with ambient intelligent we do not mean "disappearing technology" but more so technology that proactively assists people in their daily lives [5]. In our case, the Affective NSS detects the context of the user, i.e., the user's emotion and the negotiation process at hand, and suggests to the user possible negotiation behavior. As such, typical ambient intelligent research themes such as multimodal context sensitivity [137], trustful persuasion, and low-invasive emotion detection [1] are very relevant in two senses: the development of an Affective NSS will benefit from existing research and will contribute to these research themes.
The rest of this article is structured as follows. First, we define emotion concepts and negotiation concepts to facilitate the discussion in the rest of the article. Then, relations between emotion and negotiation will be strategically reviewed to show the richness of the interplay between emotion and negotiation. Second, we structure the relations between emotion and negotiation. This structure is based on the emotion and negotiation concepts defined earlier as well as the reviewed relations between negotiation and emotion. We use this structure to discuss the affect-related support functionality of an affective negotiation support system, i.e., how can such a system help negotiators cope with the relation between emotion and negotiation. Finally, to identify the feasibility of the discussed functions, we briefly review the affective computing literature, i.e., the field of research aimed at measuring, modeling, expressing and using emotion in computerized systems [120, 121].

\section{Emotion and Negotiation}

In this section we detail the notion of negotiation. We also detail the notion of emotion. After that we give a short overview of existing relations between emotion and cognition, as well as provide a more focused overview of different ways in which emotion and negotiation influence each other.

\subsection{Negotiation}

Negotiation is a process in which two or more parties aim to reach a joint agreement regarding an exchange of goods and services. A key aspect of negotiation is that neither of the parties involved can reach a solution by itself [144]; interpersonal decision making is always involved. Further, negotiation is a phenomenon that is influenced by culture [74]. People in different cultures have different negotiation styles [132]. Negotiation also plays an important role in human life, not just in politics or when buying a house. Many situations can be approached from a negotiation point of view, and in fact are negotiations, although simple and short ones. These situations are not limited to buyer-seller interactions, as is often believed by non-professional negotiators. Consider for example the following typical evening interaction between John and Jane.

Jane: "Our kid is getting tired, John will you put him to bed today." 
John: "Sure, will you tidy up the kitchen a little bit."

Jane: "Let's do that together, cause it's quite a mess, and I made dinner already."

John: "Ok, that's fair, would you then please prepare the bottle for the little one while I change him, so that we can quickly finish everything and watch the evening news?"

Jane: "Ok".

This is a common situation in which a household package deal is concocted about what has to be done, why it has to be done now and who does what. We don't think about this as negotiation, but it actually is. There are issues and preferences involved (who does the kid, who does the kitchen, who cooks), there is the exchange of bids, the introduction of new issues (prepare the bottle), making compromises (do the kitchen together), and trying to get to a joint outcome (watch the evening news).

The main goal for a negotiation is to reach an agreement that is beneficial to all of the involved parties. Here we give an overview of the most important steps in the process and the variables involved. Negotiation starts much earlier than inexperienced negotiators realize. Four major stages can be discerned (Figure 1a): private preparation, joint exploration, bidding, and closing, see e.g., [73, 144].

The first stage, private preparation, is about information gathering and reflection before meeting the other party. The negotiator investigates the negotiation domain, his/her profile and that of the opponent. In this phase the negotiator typically defines his/her preferences, thinks about alternative outcomes (also called options or alternative deals), the desired and minimal outcome (called target point and reservation point, respectively), the best alternative to no agreement (BATNA), identifies the other party, what their BATNA is, as well as whether the negotiation has a long-term, one shot or repetitive nature, whether the negotiation involves ideologies or resources, and whether negotiation agreement must be reached [144]. Whether a negotiation is a long-term, one shot or repetitive one is particularly important as this influences the negotiation process and strategy quite a lot. For example, when buying a car at a dealer that is not your own (one-shot negotiation), claiming value can be done quite "aggressively" as there is little risk in harming the relation (there is none).
In the second phase, joint exploration, the negotiating parties get to know each other, but don't place bids on the table. The aim is to check the information gathered so far, to create a good atmosphere, get to know the other persons, their role, power, mandate, and bargaining style, to investigate potential options, identify useful negotiation styles, and to agree upon a protocol for the bidding.

In the third phase, bidding, bids are exchanged. For each incoming bid the negotiator has to decide whether to accept, make a counteroffer, take a break, or stop (when a better alternative exists elsewhere). During this phase, the bidding strategy plays an important role. Also, it is important to keep track of alternative options, your reservation point and your BATNA during this phase. Each bid has to be checked against these.

Two aspects during the joint exploration and bidding phase are particularly important: creating value and claiming value [144]. Creating value is about "making the pie bigger", i.e., increasing what can be divided amongst the negotiators by introduction of new issues important to both, exchange of information about preferences about issues, and the development of package deals not single issue deals. Claiming value is about "slicing the pie" in such a way that you get equal or more than your reservation point (the lowest acceptable value of a deal). Claiming value is a distributive process, creating value is a collaborative process.

In the fourth phase, closing, the outcome of the bidding stage is formalized (e.g., in contractual form) and confirmed by both parties. If necessary (e.g., parts of the deal are not clear), the negotiation returns to one of the previous stages. Although relation management is important during the complete negotiation process, it is particularly important in the closing phase [144]. After the closing phase, negotiators part, and regrets and wrong impressions can be formed. If the negotiation was a long-term or repetitive one, a successful closing phase is essential for future negotiations and relations.

In the section on affective negotiation support system we use the four phases and negotiation variables to structure the possible roles affect could play in each phase and for each variable. 


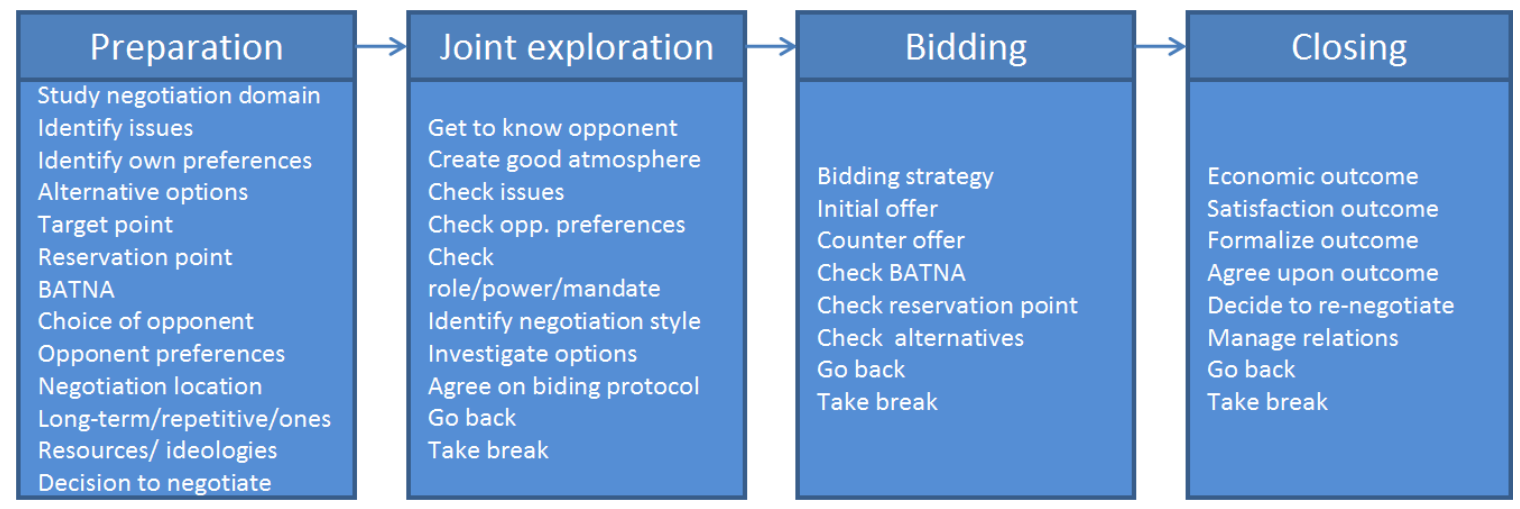

Figure 1a. Four negotiation phases with most of the important activities in each phase.

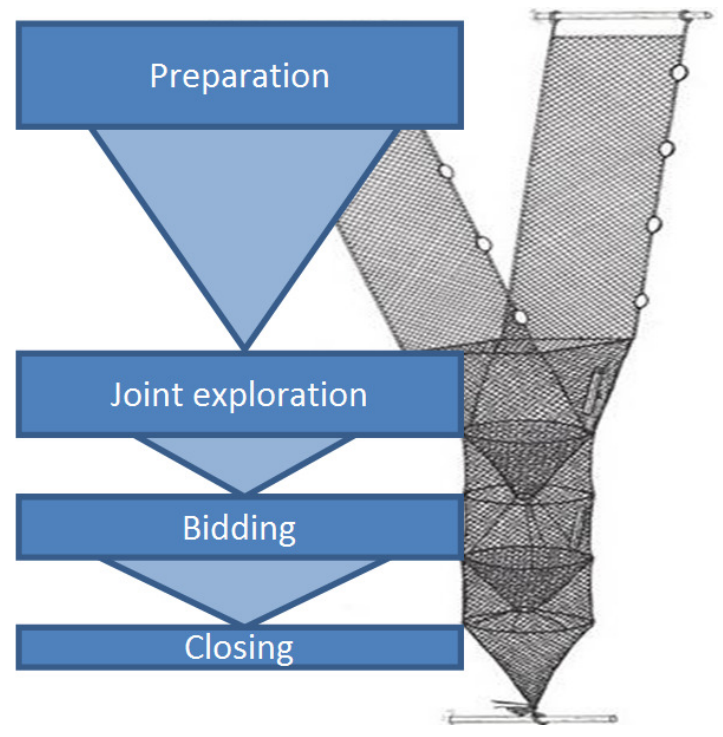

Figure $1 \mathrm{~b}$. Hoop net view of the negotiation process. It is easy to go to the next phase but difficult to go back to a previous phase.

\subsection{Definition of Affective terms: Mood, Emotion, and Attitude}

Until now we have talked about emotion and affect as if it were one thing. Emotion, however, is a complex topic, and agreement on one solid definition does not really exist. We will not attempt to define emotion here, as many excellent works have been published from different perspectives that together do much more credit to the diverse and multimodal nature of emotion $[60,91,95,106,113,116,120,128$, $131,135]$. In this section we explain what the different emotion-related terms usually refer to, and the above-mentioned references are a collective source for this explanation. We do so because in later sections we use these terms to explain and structure the different relations that exist between affect and negotiation. Most notably in the section on affective negotiation support systems we use these terms to identify the different roles emotion, mood and attitude can play in such systems.

Affect (as in affective science) is the commonplace term for everything that has to do with emotion, including emotion, mood, affective attitude and emotional traits. Emotional traits are long term predispositions of a person to be in a particular emotion or to react to events in a particular emotional manner. Although important for negotiation, we do not consider emotional traits in this article. Emotion, mood and affective attitude are different but strongly related and influence each other. In general, an emotion is comprised of a facial expression, feeling (the conscious experience of the emotion), cognitive processing aimed at evaluating the situation in terms of personal relevance, physiological change and action readiness. Furthermore, emotion refers to a short but intense episode that, in addition to the previously mentioned aspects such as facial expressions, is characterized by "attributed affect to a causal factor". An emotion is a noticeable and usually powerful experience. For example, I feel (and notice I am) happy when seeing an old friend. In contrast, mood refers to a silent presence of moderate levels of affect, not necessarily related to the preparation of action. Mood is not (consciously) attributed to a causal factor. I can feel frustrated for half a day without knowing why. Affective attitude refers to affect associated with something or someone, in contrast to affect arising because of that thing or person. An affective attitude is an affective association coupled to a thing or person, an emotion is an evaluation of a thing or person 
in terms of personal relevance. For example, I like a particular popular science book I read (existing affective association) versus I like you because you just invited me over for dinner (attribution of affect to causing event/person). The essence of an attitude is that it is preexisting affective information that is associated with concepts or persons. To complicate matters a little, affect is also used to refer to a particular view on emotion and mood, in which multiple dimensions (usually two or three) are used to describe the core of emotion and mood (see below).

There are several theoretical views on how to think about (and computationally model) emotion. These views can be categorized in multiple ways, but the following categorization has been used quite often in literature and is based on the way emotion is represented: as categories of emotion, dimensions or principal factors, and components that form an emotion.

\subsubsection{Discrete emotions or categories.}

The literature on categories of emotion is extensive. For this paper, we limit ourselves to an example: Ekman and Friesen proposed the following six universal facial expressions: anger, fear, disgust, surprise, happiness, and sadness [48]. The essence of emotion categories is that each emotion has a unique "multi modal program" associated with it (e.g., fear, arousal, flight, sweating are all part of the fear "program"). For an overview of literature on emotional categories see [37]. In experimental research that studies the influence of emotions on behavior (e.g., negotiation), emotion is often equated with particular discrete emotions.

\subsubsection{Dimensions.}

Research on emotion dimensions proposes that each emotion (and affect in general) can be described using several affective dimensions [14, 107, 131]. The essence of this perspective is that a limited set of dimensions can describe a large set of emotions by emphasizing commonalities (e.g., core physiological activity [131], or approach versus avoidance) between emotions, and deemphasize the uniqueness of individual emotions. An important representative of this perspective is the pleasure (valence), arousal, and dominance (PAD) model [107]. In this model the dimension pleasure refers to pleasantness of the emotions, for example by qualifying the emotion as positive or negative. The arousal dimension refers the extent of bodily activation. The dominance dimension refers to whether the subject is in control, or the environment. Most emotion psychologists agree that at least pleasure (whether affect is positive or negative) and arousal are core dimensions of affect. The dimensional approach is particularly important for mood, as in experimental studies (including those on affect and negotiation) the mood of a subject is often defined in terms of these dimensions, usually valence but sometimes also arousal and dominance.

\subsubsection{Components.}

The third perspective on emotion is the componential view, of which cognitive appraisal theory is a prototypical member. For an overview of appraisal theories, see [50]. Emotions are defined as "valenced reactions to events, agents, or objects, with their particular nature being determined by the way in which the eliciting situation is construed" ([113], p. 13). The essence is that different cognitive processes (components) result in an interpretation of a situation and that this interpretation is a major explaining factor in emotion. It has become a standard model for synthesizing emotions in computers [120] and proved useful for computational reasoning about emotions [140]. This view on emotion is rarely used in experimental studies aimed at understanding the influence of emotion on negotiation, although exceptions exist [23].

Emotion is a multimodal phenomenon and studying it benefits from a multidisciplinary standpoint. Across disciplines, there exist commonalities. For example, many emotion researchers believe that there are two common affective factors that are useful to describe a mood, emotion or attitude: valence and arousal. Within a discipline, these factors can be studied in different ways: are these factors the psychological core of emotion, which areas or mechanisms in the brain are involved, are these always independent (orthogonal), are they artifacts of statistical analysis of many factors, etc. Other common views exist, for example, with regard to theories that explain emotion elicitation (where does the emotion come from). Most agree that an emotion is the result of an evaluation of the situation in terms of personal relevance. It depends on the discipline which aspect of this evaluation is highlighted. Is it a cognitive evaluation, is it conscious, holistic, component-based, automatic, biologically hard-wired, social, etc.? For a recent overview and reflection upon emotion elicitation, see [67]. For a quick and broad introduction to the different emotion theories and the history of these see chapter 5 in [51] or chapter 3 in [91].

An important distinction in the context of negotiation is felt versus displayed emotion. These need not 
be the same (consider, e.g., strategic use of emotion and expression suppression), and the effects on the negotiation process are not the same either, as we will see in the next subsections. In the rest of this article we will use the terms emotion, emotion display, mood, attitude, and affect as described in this section.

\subsection{Generic relations between emotion and cognition}

There is a long history of research into the influences of affect on cognition. As affect has been found to influence thought and behavior in many ways, we provide a brief overview of the main findings.

Emotion is related to the urge to act, see, e.g., [59]: run away when in danger, fight when trapped, laugh and play when happy. Specific emotions trigger specific behaviors (e.g., fight or flight). So, emotion is not only related to the urge to act, some emotionswhen strong enough - make us really act.

$>$ In general, emotion motivates behavior.

Emotion and feelings influence how we interpret stimuli, how we evaluate thoughts while solving a problem [39] and how we remember things. A person's belief about something is updated according to emotions: the current emotion is used as information about the perceived object [58, 63], and emotion is used to make the belief resistant to change [61]. Ergo, emotions are "at the heart of what beliefs are about" [60]. This is important for negotiation, as preferences about issues are in fact beliefs about issues.

$>$ Preferences therefore have an important affective quality.

Affect influences information processing in humans; positive affect facilitates top-down, "bigpicture" heuristic processing while negative affect facilitates bottom-up, "stimulus analysis" oriented processing [4, 58, 63, 110, 119]. Positive affect is associated with flexible and creative problem solving, while negative affect is associated with critical evaluation of stimuli. Affect also influences attention and working memory in particular. Positive affect increases working memory performance by facilitating switching to a new cognitive set (updating the contents of working memory) [46]. Positive affect also impairs working memory performance as indicated by lower performance on planning and deductive reasoning [111], perhaps due to higher distractibility [46]. In these studies, affect is interpreted as moderate levels of valence (positive or negative mood), and the influence on cognition is at a metalevel (affect as parameter). A second way in which affect influences processing is by inducing biases in the decisions made during the process. For example, when in a positive mood people tend to think of positive things thereby biasing the options they generate during a decision making process (mood congruency: mood favors associations compatible with that mood). Furthermore, the extent to which mood influences reasoning and decision making is dependent on the type of information processing employed by the person [58]. For example, elaborate decision making in which many novel options are evaluated and generated is prone to affective biases, while motivated processing guided by a clear goal is not.

$>$ These findings show that mood influences information processing.

Further, and important for negotiation, affect influences judgment. It has been shown that positive affect renders people less critical with regards to the strength of a persuasive argumentation [100]. This could be due to reduced cognitive capacity [100], but also due to a tendency of people in a positive mood to be prone to a heuristic form of processing in which they use prior beliefs to form judgments instead of extensively analyze the argumentation itself (for an overview see [54]).

$>$ Regardless the underlying mechanisms, mood influences judgment.

Many of these studies are based upon the idea that valence is the component to look at when investigating the influence of affect on cognition. However, specific emotions have specific effects on cognition. Of course, being happy and enthusiastic makes you feel optimistic about the future, but interestingly, angry people also make optimistic judgments about future events, while fearful people make pessimistic judgments [93]. Also, angry but not sad subjects used a more heuristic-based processing approach in stereotypic judgments [12].

$>$ Not only mood, but also specific emotions have specific effects on cognition.

In this short overview, we have seen that affect influences cognition in at least the following ways: emotion motivates behavior; emotion influences beliefs; mood influences information processing; mood influences judgment; and there are emotion specific effects. 


\subsection{Relations between emotion and negotiation}

In the previous section we have reviewed some of the important influences of affect on cognition. There are also negotiation-specific relations between affect and cognition. We now review some of the main findings of experimental studies into the relation between affect and negotiation.

\subsubsection{Positive affect.}

Although it is debatably whether being elated or extremely funny has positive effects on a negotiation, positive affect in general has a beneficial influence on the negotiation process, outcome and relations. Positive affect increases the tendency to use a cooperative integrative style [7, 27]. Positive affect induced through smell decreases the tendency to handle conflicts with avoidance and competition, and increases the size of monetary goals and number of concessions during negotiation [6].

Having one emotionally intelligent person in a dyadic negotiation (i.e., two parties involved) is related to more value creation (when two persons negotiate over a deal consisting of issues and each issue has a number of points of fictive value for each person, the created value of a final deal is the sum of the points over all issues for both persons; emotional intelligence is related to perceiving emotions, using emotions, understanding emotions, and regulating emotions [151]). However, the emotionally intelligent person is unable to claim that value (measured as the portion of points the emotionally intelligent person received as bargaining outcome), resulting in more value for the other party [42]. A potential explanation is the tendency of emotionally intelligent persons to be cooperative, trusting and to favor a good atmosphere [42].

As discussed earlier, such a positive attitude helps the generation of integrative solutions, but perhaps not to subsequently claim what should be yours. Related to this is the work described in [3]. The authors find that having a positive affective personality trait again favored reaching integrative deals, and did not negatively affect the creation of value (joint outcome).

$>$ Positive affect fosters a cooperative approach but might hinder claiming what is yours.

\subsubsection{Negative affect.}

In general, a negative mood and more specific felt anger and fear have a negative influence on the negotiation process [2]. In particular felt anger has nega- tive influences on the negotiation with respect to the integrative character of the negotiation [138]. Negotiators who feel angry create less value.

However, expressing anger can be a good strategy in claiming value, but only if the opponent has poor alternatives [138]. Interestingly, anger expression did not affect the creation of value in this study, meaning there is no negative side effect with respect to the integrative character of the negotiation. A further restriction on communicating anger is the observation that anger communication is useful for enforcing high offers from an opponent, but only if the opponent does not have the opportunity to deceive the other and when rejecting an offer has consequences [45]. While anger expression does force the other party into making concessions, the expression of anger during a multiparty negotiation may exclude the anger expressing party from further forming of coalitions [9]. This means that anger might help you get more, but it might also exclude you from further negotiation. It is also important how to communicate anger (and happiness). Anger directed at the other party is less effective at eliciting large concessions than happiness directed at that party, while the role of anger and happiness directed at offers is reversed [139]. This means that, while useful, expressing anger is a rather delicate tactic.

Feelings of guilt after a round of negotiation combined with a competitive strategy during that round positively influence cooperation behavior in the next round in a repeated social bargaining game (prisoners' dilemma) [82]. Although this study is not directly related to dyadic negotiation in the strict sense (exploration of issues, options, bidding, closure, etc.), it is relevant. It shows that in repeated negotiations, feelings of guilt can influence negotiators to choose for a more cooperative solution (win-win) in the future instead of a competitive one (win-lose).

$>$ Felt negative affect has a negative effect on integration, except guilt which favors cooperation; expressed anger can help claiming value, but expressing anger is not without risk.

\subsubsection{Contradictions between positive and negative affect.}

Slightly contradicting to the positive effects of anger expression are the findings by [86]. They find that displaying positive or neutral emotion, but in any case not negative emotion, is a better strategy at both gaining concessions from the opponent as well as the likelihood to close a deal (and have a long-term relationship). Apparently, the display of both positive 
and negative emotion can help claiming value, but when this exactly happens depends on the negotiation task (the tasks in the last two studies were different) and context (such as alternatives, perceived power, consequences, culture, etc.).

The relation between perceived own power and perceived anger of the opponent has been confirmed in a large study [85]. It was found that variables such as having more alternatives and a better BATNA influence the perceived level of power, and that this counteracted the effects of anger expression of the opponent, such that the usual effect of an angry opponent (more concessions) was void. In another study, a compatible finding was found [84]. If a person in a dyadic negotiation perceives the emotion of the opponent to be angry (as opposed to neutral or happy), that person concedes more easily but only if (a) the person has low power perception of itself in the negotiation (low number of alternatives), or (b) the person has no time pressure in the negotiation, or (c) that person's personality has a low need for cognitive closure (cognitive closure means having a need for clear rules, motivations and goals, and a tendency to quickly form conclusions). This indicates that the context of the negotiation influences the way negotiators process information, and the more the context favors clear motivated processing, the less the negotiator is influenced by anger of the opponent [84]. Further, given the fact that an important mediating factor is perceived power of the self and the opponent, it could well be that communicated/perceived power is the responsible factor for the effect of happiness and anger expression. Both happiness and anger are high power (dominance) emotions [106].

$>$ The communication of and perceived level of power (dominance) seems to be the common factor in anger and happiness expression effects on claiming value. Motivated processing limits the effects of anger expression.

\subsubsection{Mood and process.}

The perception of a negotiation being a fair process influences the affective reaction about the process [71]. If, during a negotiation the process is perceived as fair, the negotiation itself is seen as more positive and vice versa. Additionally, a positive perception of the process is positively related to the economic size of the outcome gained by a negotiator (claimed value). This could indicate that being happy about the process helps getting a good outcome (although the study cited cannot conclude this because this involves causality, and both measures were taken after the outcome, so the inverse relation can also be true: good outcome, therefore happy with the process).

It has been found that mood is contagious during a negotiation setting [8]. In a negotiation exercise where fictive rewards had to be distributed amongst the participants in the negotiation (group size was 2-4 persons), the mood of the participants was significantly influenced by the mood of a secret confederate added to the group (as an extra group member). Positive affective manipulations by the confederate resulted in a more positive mood in the group and vice versa. Further, a positive mood resulted in both cooperative behavior (measured as the standard deviation in the distribution of reward among the participants in a group) and less conflict.

In fact, several of the findings just reviewed are compatible with the affect infusion model as proposed by [58]. This model proposes that the extent to which affect influences information processing depends on the processing style. The results in the study by [84] indicate that motivated information processing, a type of processing where there is a clear definition of outcomes, is less influenced by affect. Compatible with this analysis is the proposal by [64]. They argue that complex negotiations (and cross-cultural negotiation is the example they take) are usually done in the substantive processing mode [58], a mode characterized by complex judgments, open ended goals, and new information. The substantive processing mode is prone to affect infusion (i.e., mood congruent associations influence the reasoning process). As a result, mood strongly influences the reasoning process and this can result in a vicious circle [64]. The authors propose to approach complex negotiations from a motivated processing point of view, as this is a more goal-oriented form of reasoning and less prone to affect infusion. We think that for non-professional negotiators many negotiations can be considered complex ones, and therefore this is an important finding in general.

$>$ Together, these findings indicate that mood is an important factor for the course of a negotiation: it influences the mood of others, and a positive mood makes the process more cooperative and less conflicting and influences the economic outcome.

\section{Affective negotiation support systems}

In this section we work towards affective negotiation support. First we briefly explain the current state of the art of negotiation software. Then we provide a 
structured overview of the relations between affect and negotiation just reviewed. We use this overview to discuss the functionality an affective negotiation support tool could offer to help coping with or strategically use affect in negotiation.

\subsection{Negotiation software}

First, we briefly discuss current negotiation software. Apart from research into negotiation mediated by technology, such as e-mail and other digital communication means [143], two areas of research related to negotiation software can be distinguished: negotiation support systems (NSS) and automated negotiating agents (ANA). Whereas the focus of NSS is on helping a user to negotiate by means of structuring the process and offering analysis support (in essence a special purpose decision support system), ANA are aimed at automating (parts of a) negotiation completely [73] We will now give a brief overview of existing negotiation support systems and automated negotiation agents..

NSS can be used in different kinds of usage contexts. A high-level distinction of contexts into the categories preparation and training versus real-time usage has been identified by negotiation experts [123]. The preparation and training context refers to use of the system while structuring preferences, identifying alternatives, reflecting upon the process, in short, usage in which there is no direct contact with the other party involved in the negotiation. Real-time usage refers to those situations where parties are in direct (but not necessarily face-to-face) contact. Further, such a system can have different roles in the negotiation process: mediation or personal adviser of one of the parties. Inspire (http://interneg.carleton.ca/inspire/) is a Web-based negotiation support system. It contains a facility for specification of preferences and assessment of offers, an internal messaging system, graphical displays of the negotiation's progress, and other capabilities. It has been used to support humans in negotiation as well as to collect data about such negotiations for research purposes. One of the main benefits of Inspire is its ability to offer the user a structured approach to prepare and engage in a negotiation, and its use as a training tool. Another NSS example is provided by Athena (www.athenasoft.org) that has been primarily used in education. As is the case for Inspire, users of Athena have to build content models themselves. That is, preferences are elicited from the user who has to provide the domain structure as well. The provided support does not include predefined repositories of content models, interaction support, or assistance in selecting a bidding strategy. As a final example, Smartsettle (http://www.smartsettle.com) is a commercial negotiation support system that also provides bidding support. Interestingly, while other systems keep offers and demands hidden, Smartsettle displays proposals and suggestions to all parties (a mediation perspective).

With respect to automated negotiating agents (ANA), in the past decade various models have been proposed and many results on the performance of such agents have been published [24, 80, 109, 124]. The research has mainly focused on devising strategies, protocols, and negotiation languages, i.e., languages to represent negotiation domains [88, 129, 142]. Among others, it has been demonstrated and replicated that automated negotiating agents may obtain significant improvements over the outcomes obtained by humans; see e.g., [13]. Typically, in the automated negotiation literature concession-based strategies have been proposed. A concession-based strategy proposes as a next offer a bid that has a decreased utility compared to the previously proposed offer. An example of such a strategy, which does not use any domain or opponent knowledge, is the timedependent strategy [52]. The time-dependent strategy decides on a negotiation move based on considerations derived from the agent's own utility space only. Such a strategy cannot search through the negotiation outcome space for outcomes that are mutually beneficial for both parties and thus is not always able to reach so-called win-win outcomes $[96,125]$. A timedependent strategy will therefore most likely be inefficient in complex negotiation domains and reach suboptimal agreements. An additional problem in negotiations occurs when the preference spaces of the negotiators are non-linear. However, new solutions are being forward, see e.g., [53, 102]. Another complicating factor is the problem of incomplete information. Approaches have been put forward to learn an opponent's preferences given the negotiation moves that an opponent makes during the negotiation, see e.g. [26, 33, 72, 79, 97, 112, 114, 152]. For example, negotiating agents can obtain a good approximation of an opponent's preferences in a singlesession negotiation by studying the offers made by the opponent, see [72]. The above techniques are applicable not only in automated negotiation, but also in the area of negotiation support systems, that is getting more attention over the years, see e.g., [31, 73, 81, 98]. 
In this article we focus on the use of an NSS as a personal advisor, in both the preparation, as well as real-time phases. Further, in this article we focus on negotiation support systems, not on automated negotiation agents (although ANA technology can be part of an NSS, e.g., when preparing bids or bidding strategies). As can be seen in the previous review, negotiation support systems (and ANA) support negotiators with the rational part of the negotiation process such as exploration of issues, identification of alternatives and calculating bids. Affect plays an important role in the negotiation process, as we have seen in the literature reviewed previously. Therefore, we claim that negotiation support systems should help negotiators cope with the interplay between affect and the negotiation process. One way to do so is by installing an NSS as a trusted "rational" mediator in between negotiators in emotional situations, for example as proposes by [10]. Now the role of affect is addressed by trying to minimize it. In the next section we propose a different approach, namely, to explicitly embed in the design of an NSS the support for the different roles affect can play during a negotiation.

\subsection{Affective negotiation support systems: functionality}

In this section we propose affect-related functions a negotiation support system could have. We organize the discussion of functions according to the structured overview of the relations between affect and negotiation as found in the psychological studies reviewed earlier (Figure 2). This overview has two dimensions. Our first dimension is the negotiation phase (as previously defined in the Negotiation section). This approach is compatible with the one proposed in [7] in which the different influences of affect are also categorized according to the phase of the negotiation. We use slightly different phases, i.e., we have separated the negotiation phase in [7] into joint exploration and bidding, and merged their outcomes and implementation phases into one phase called closing. Our second dimension is the type of affect involved (as previously defined in the Emotion section). We have taken the four different types of affect as described earlier. Our approach is compatible with, but also slightly different from, the one described in [145]. The authors separate emotions that exist before the negotiation (called exogenous emotion) and emotions that are felt during the negotiation (endogenous emotions), compatible with our distinction of the negotiation process in phases. Further, they distinguish between felt and expressed emotions, equivalent to our distinction between emotion display and emotion. We introduce two extra distinctions, based on the previously discussed affect-cognition literature, being the distinction between mood and emotion, and emotion and attitude. The reason for doing so is that attitude is quite different from both mood and emotion (as explained earlier), and emotion and mood have different influences on cognition and behavior (mood has global, subtle influences, while emotion has direct, strong influences).

The discussion of possible affect-related functions of negotiation support systems (NSS) is organized in order of negotiation phase (top-down in Figure 2). Functions are to be interpreted as functional requirements an affective NSS could have. All functions are numbered and presented as conclusion to an introductory paragraph. First we describe how generic influences of affect on cognition could be used in a negotiation support system. Then we describe for each phase potential affect-related functions. All of the hypothesized functions are based on findings from the affect-negotiation literature just reviewed. We focus on online "light" support not offline "deep" training. This distinction into two types of support has been proposed by negotiation experts [123]. An example of offline training, i.e., virtual reality scenario-based training, will be discussed in a separate paragraph at the end of this section. The feasibility of the different functions we propose for an affective NSS will be discussed in the section on affective computing techniques.

\subsubsection{Generic affective support.}

Emotions are strongly linked to motivation. The genuine expression of an emotion is therefore an indication of underlying concerns, beliefs and desires. This means that the expression of emotion during the negotiation process should be taken as a signal. Especially as specific emotions signal specific meaning, for example fear signals a pessimistic view on the future, while anger and enthusiasm signal an optimistic view of the future. Such signals can be taken into account during the negotiation in two different ways: as something to cope with, or as something to use strategically.

$>$ 1a. The NSS detects the felt emotion of the negotiator and his/her opponent, and indicates effects according to the generic influences of felt emotions.

$>1 \mathrm{~b}$. The NSS detects the expressed emotion of the negotiator and his/her opponent, and indicates ef- 
fects according to emotion display in different phases and suggests changing expression.

The same holds for the influences of mood. Mood influences information processing in important ways. Positive moods favor creative, big-picture integrative thinking, while negative moods favor critical evaluation of details. An NSS can help to make someone aware of one's mood and the effects this mood can have on the decision making process. For example, it is necessary in a negotiation process to consider if the negotiation is ready to move to the next phase. Did we explore enough options? Did we exchange enough information of issues? Can we now start bidding? Negotiators moving through the different phases can be seen as fish swimming into a hoop net (Figure $1 b$ ); it is easy to move on, but difficult to get back.

$>2$. The NSS detects the negotiator's mood and if the negotiation is moving towards the next phase. The NSS indicates to the negotiator whether his/her mood is compatible with critically analyzing the current phase. Positive moods should be avoided, neutral or slightly negative mood are favored.

A related issue is that it is difficult to decide to go back, as this usually involves more effort and it might be perceived as offending by the opponent. As such, an NSS can help a negotiator to "gracefully" step back by giving canned sentences, but also ask the negotiator how he/she feels about going back. If this results in a negative emotion, the next step is to work on a strategy to go back that does feel good. If a negotiator ends up in the closing phase not feeling good about the solution and not feeling good about going back one or two phases, then that will result in a bad deal.

$>$ 3. The NSS periodically asks the negotiator about his/her attitude about the "decision to step back", raises a red flag when this attitude is negative, and helps identifying a "step back strategy" that feels good.

Further, mood can influence attitudes, and thereby opinions about opponents, issues and options. A positive mood triggers information that has a positive affective association and vice versa (mood congruency). Further, the current mood, if one is unaware of it, influences how beliefs are evaluated (mood as information). This means that while evaluating options, issues and preferences, one should be aware of two things: first, did I (we) cover a broad range and not just the mood-congruent range, and second, did we evaluate the options, issues and preferences in an objective way?
$>$ 4. The NSS detects the negotiator's mood and if the negotiator is identifying / evaluating options, and indicates potential dangers of mood congruency and mood as information.

$>$ 5. The NSS detects negotiator's mood and if the negotiation is in a phase characterized by an elaborate reasoning style (open ended reasoning and new information), and either indicates potential dangers or offers to cope with the situation by structuring the negotiation process to enforce a motivated processing style (e.g., helping the negotiator(s) to set clear goals).

\subsubsection{Preparation phase support.}

In our literature survey we have not found many negotiation-specific influences of affect in the preparation phase, probably because negotiation experiments mostly focus on the exploration and bargaining part and not on the preparation part. However, as the preparation phase essentially is not a negotiationspecific phase, but more so an information gathering and preference analysis phase, we will outline some of the possible functions for an NSS based on the reviewed generic influences of affect on cognition. First, it is essential to get a good overview of the options, issues and your preferences. It is useful to both vary your mood during this phase (i.e., explore issues not only when in a good mood, but also when in a bad mood) and be made aware of your mood.

$>$ 6. The NSS continuously detects negotiator mood while he/she is working on preference elicitation and analyses "mood" coverage. If needed, it advises to think about preferences in different moods.

It is equally useful for a negotiator to become explicitly aware of the emotions you are likely to feel during the negotiation when preparing for the negotiation (e.g., when negotiation is perceived as something difficult, the negotiator might feel fear).

$>$ 7. The NSS measures the negotiator's attitude with respect to target point (goal), reservation point, issues, opponent and the decision to negotiate in the first place. If negative attitudes are detected, training is advised after which the NSS re-measures attitudes.

An NSS can in fact play an important role in practicing negotiations. A virtual scenario can be played out with an artificial intelligent agent that is able to simulate negotiation choices and affective reactions. By playing the scenario, you could try out different strategies and get accustomed to the idea of having to negotiate about particular (perhaps emotionally laden) issue. Training will be discussed in more detail at the end of this section. 
Finally, for a negotiation support system (and in particular bidding support) it is essential that users input valid preferences for the different issues that play a role in the negotiation. Currently, user preferences about issues and options are usually modeled on a one dimensional scale ranging from good to bad. Users might benefit if an NSS is able to model affective preferences about options and issues. For example, I am disappointed if this would be the price for the new car. I am happy if I would get metallic paint for free. I would be angry if I end up at my reservation point. Such affective preferences can be modeled in different ways. For example, one could represent a preference numerically on the different affective dimension such as pleasure, arousal and dominance. Another example would be to include particular discrete emotions as issues about options and allow the user to rate the importance of different emotions, e.g., it is very important that I do not have any regret, or, it is very important I am happy.

$>$ 8. The NSS is able to elicit affective preferences (and use these for bidding support later on).

\subsubsection{Exploration phase support.}

In the exploration phase, emotion plays an important role. First, it is important to limit the amount of felt anger (or sadness and fear for that matter). Obviously, one cannot just suppress these feelings, but one can take breaks, continue the negotiation another time or try to identify what exactly makes one angry. Such negative emotions hinder an integrative approach as well as the creation of value (win-win potential). An NSS can detect anger and suggest such steps. As an example consider the work by [78], who identified the role of anger in computer mediated negotiation. They found that flaming (hostile emotional communication) was completely mediated by anger resulting from (a) frustration resulting from the communication medium (text chat in their case), (b) uncertainly about the negotiation task, and (c) anger directed at the other party. They propose three steps negotiators can take to reduce anger: reinterpretation, managing provocation, and relaxation.

$>$ 9. The NSS detects felt anger, sadness and fear by the negotiators and tries to manage the situation by making negotiators aware of the moments in which anger was detected and suggesting taking a break.

A negative mood can hinder an integrative approach as well. A positive mood favors integrative problem solving and creativity, and helps to avoid conflicts. These are important aspects in the joint exploration phase, as one of the major goals is to explore options. Exploration requires a creative and flexible mind set.

$>10$. The NSS detects the overall mood (e.g., average of, and difference between moods of both negotiators) and indicates if the mood is compatible with the beginning of the exploration phase.

People in a good mood also set high goals. This might be a good thing, depending on the negotiation context. If the negotiation is perceived as very complex, or the opponent is not someone to do big concessions, it is perhaps better to not set your goals too high, and therefore favor a less enthusiastic mood. As a positive mood also favors heuristic decision making (not detail oriented) and hinders making correct judgments by making a person accept propositions too easily, it is important to balance the mood, also during this phase. As it is important to cover the scope of issues and options as good as possible, this also involves critical analysis of these issues and options. This is favored by a negative (or at least slightly negative to neutral) mood.

$>$ 11. The NSS detects the overall mood and whether enough information is generated and suggests that it is time to change mood and critically analyze the data.

> 12. The NSS explicitly breaks up the exploration phase in a "positive brainstorm phase" and a "neutral/reserved analysis phase".

$>$ 13. The NSS facilitates the right mood through standard mood induction techniques such as showing short movie clips with either positive or negative affective content.

Any mood has the risk of mood induction; the influence of mood on attitudes in this case about for example the negotiation issues, options, and opponent. This means that a person's mood will both color the associations he/she has and limit the kind of associations available. If the goal is to have a broad look, it might therefore be a good strategy to keep a neutral mood, or vary the mood across the positivenegative spectrum, as discussed above. An alternative strategy is to pick an information processing style that is less prone to these two effects: motivated processing. An NSS could help negotiators by setting clear goals and structuring the process. This in and of itself might already reduce the influence of mood on judgment and attitudes. Functions 4 and 5 already cover these issues.

\subsubsection{Bidding phase support.}

In the bidding phase emotion expression seems to be important. Both positive and negative expressions 
(happiness and anger, respectively) can help to claim value by making the opponent do high bids and more concessions. However, anger expression can have obvious negative side effects, and anger only has a positive effect on claiming value if the opponent feels less powerful (poor BATNA, poor alternative options, no ability to deceive, rejection has consequences). An NSS can help to identify when anger expression is useful and how anger could be interpreted. Consider for example the findings by [122] who show that selective use of anger and happiness expression can have a positive effect on the "fixedpie" perception of negotiators. They showed that when anger is used as a reaction to another party's low priority issue in a bid and happiness to that party's high priority issue in that bid, that party's fixed-pie perception is reduced. When anger and happiness were inversed, the effect on fixed-pie perception was reversed too. This indicates that affect can also be used as information about issue priority. $>14$. The NSS detects expressed emotion by the opponent and indicates what these signals could mean according to the relations depicted in Figure 2.

$>15$. As the NSS keeps track of options, preferences and issues as well supports the user in calculating bids, it can suggest the use of anger (or enthusiasm, see below) expression as a tactic to force an opponent into giving up value when it estimates that the opponent has a low-power position.

$>$ 16. The NSS analyzes if the "expression tactic" worked by analyzing the value of the counter offer.

$>17$. The NSS adapts its bidding strategy according to the "expression tactic".

Strategic use of emotion expression can be made dependent on the relation between the negotiators, the type of negotiation (long-term, repeated, oneshot), and the current mood. If anger expression is not an option, the NSS could suggest the use of enthusiasm expression about a particular bid. As it seems from the literature that the underlying dimension influencing the bidding is power (as communicated by both enthusiasm/happiness and anger) another way of manipulating the situation in order to claim value is by consistently keeping track of the "power situation" of both negotiators.

$>18$. The NSS detects the level of power of both opponents as calculated from objective measures such as BATNA and strength of alternatives as well as the mood. It presents these levels to the negotiator.

$>19$. The NSS adapts its bidding strategy based on the power levels of the negotiators.

A last important thing is fairness and guilt. If the bidding is perceived as fair, people have a positive impression of the process and this makes them happier about the outcome.

$>$ 20. The NSS offers a tool to enhance fairness of the bidding by explaining and enforcing bidding rules

$>$ 21. The NSS detects negotiators' attitude about fairness about the process and presents this to the negotiators as feedback.

$>22$. The NSS uses the detected perception of fairness to suggest other bids.

Related to fairness is the aspect of guilt. As guilt influences future negotiation behavior towards cooperation, an NSS can help to use guilt strategically but also help to cope with the effects of guilt.

$>$ 23. The NSS detects that you feel guilty during the bidding and suggests taking a break and reflecting upon the reason for that feeling as a protection for future negotiation rounds.

$>24$. In a long-term or repeated bargaining situation, the NSS uses opponent guilt in its bidding strategy.

$>25$. The NSS reminds the negotiator to trigger feelings of guilt in the opponent.

Apart from these more strategic uses of emotion expression, the NSS can also help creating the right information processing style (i.e., motivated processing) and manage moods as explained in the previous paragraphs and covered by the functions in those paragraphs.

\subsubsection{Closing phase support.}

In the closing phase, critical reflection upon the negotiation as well as relation building are most important. Critical reflection should occur because after signing the deal (or paying for the car) it is practically impossible to go back. It is essential to figure out if (a) you are near your target point and in any case not under your reservation point, and (b) the opponent is not under his/her reservation point. If either of the two parties is giving in too much, honoring the deal will be an issue because feelings of regret will start to develop when the two parties part. An important aspect here is outcome satisfaction.

$>$ 26. The NSS detects outcome satisfaction of both opponents (measures outcome attitude), and makes the negotiators aware of this.

$>27$. The NSS detects outcome satisfaction and uses this to propose other bids (satisfaction-based renegotiation).

Relation building is important in repeated and long-term bargaining, but less important in one-shot bargaining. Negotiators need to plan relation building 
activities even before the negotiation. As relation building is a social activity, we currently do not see how an NSS could really help in doing so. This help is probably limited to giving several hints about what could be done, such as planning dinner after an important negotiation.

$>$ 28. The NSS suggests relation building activities before and after the negotiation.

\subsubsection{Offline-training.}

The previous discussion has been about negotiation support during the actual negotiation. Now we briefly suggest several possibilities for training as part of the preparation of a negotiation using an NSS. We focus on affect-related functionality that could be provided in virtual reality scenario-based training. The training would aim for two things: first, to train a novice negotiator in negotiation skills in general, and second, to prepare a negotiator for a particular negotiation. We first discuss training generic skills. Different dynamic scenarios could be developed that involve typical negotiation settings such as job negotiation (application and contract, contract renegotiation, firing personnel), buyer-seller negotiation (car, house, appliances), and divorce. An artificially intelligent virtual character plays the role of the opponent, and the user can choose the role he/she wants. Multiple of such AI characters may be available for training. The AI-character has beliefs, desires, goals, personality, a negotiation/conflict handling style, mood and emotion. In addition to this, different scenarios are developed, each describing the negotiation setting, issues, options, preferences of the AI-agent as well as events that can occur during the negotiation. The user prepares his/her part of the scenario through instruction, and perhaps use of the NSS to structure the issues, options and preferences. While playing the scenario, the user's emotional state as well as negotiation actions (such as bids) are measured. Afterwards the user can be confronted with his/her reactions. In fact, the complete range of affect support functions described above can be used extensively during this training, as the issue of privacy (of the opponent) is less relevant and the acceptability of being measured and wired is higher [18]. Further, the user could ask the system to explain the behavior of the AI character, during and after the scenario. As the character generates its behavior in a semi-automated and dynamic way that depends on interaction with the user and events that occur in the virtual reality environment, the character will exhibit variations in its behavior every time the scenario is played. An explanation function would generate plausible explanations of the AI character's actions based on the character's internal state. Such an adaptive and dynamic virtual reality scenario is very much compatible with the idea of serious gaming (although we haven't touched the gaming aspect here).

Given that a flexible scenario system as described above exists, the user can develop its own scenarios and agents and prepare for a particular negotiation. Now, the possibility exists to fully configure the NSS's training function to train a particular negotiation setting. This can be integrated with existing tools such as preference elicitation tools and bidding support.

$>$ 29. The NSS provides a training facility to work through different user-definable scenarios (with or without affective support as mentioned in function 128). Affective reactions (mood, emotion) and user actions are logged and used as training feedback.

Table 1

Classification of affect-related NSS functions

\begin{tabular}{|l|l|l|l|}
\hline Output & $\begin{array}{l}\text { Change } \\
\text { affect }\end{array}$ & $\begin{array}{l}\text { Use affect in } \\
\text { NSS functions }\end{array}$ & $\begin{array}{l}\text { Help negotiation } \\
\text { process (tips, } \\
\text { strategy, coping) }\end{array}$ \\
\hline $\begin{array}{l}\text { Expressed } \\
\text { emotion } \\
\text { (self \& } \\
\text { other) }\end{array}$ & $1 \mathrm{~b}$ & & $1 \mathrm{~b}, 14$ \\
\hline $\begin{array}{l}\text { Felt emo- } \\
\text { tion }\end{array}$ & 9 & & $1 \mathrm{a}$ \\
\hline Mood & 5,23 & 19,24 & $2,4,5,6,10,11$, \\
& 20,25 & $8,22,27$ & $3,7,21,26$ \\
\hline Attitude & 3,7 & 17 & $12,16,28$ \\
\hline $\begin{array}{l}\text { Non- } \\
\text { affective }\end{array}$ & 13,15, & & \\
\hline
\end{tabular}

\subsubsection{Summary}

We have discussed a large variety of ways in which an NSS can help a user cope with and use affect in negotiation. However, we have not touched upon the technical feasibility of all of this. We have done so on purpose. In this section we wanted to cre- 
ate a vision, a long-term goal, of what could be done in an affective negotiation support system based on experimental data from affect and cognition/negotiation literature. To be able to implement these functions, affective computing techniques [120, 121] are needed. In order to get an idea of the technical feasibility of the described functions, in the next section we discuss the state of the art of affective computing (although only at a high-level, because the scope of this article does not permit us to go into detail), and link this to the different functions we proposed in this section. To discuss the feasibility of these functions more systematically, we classify them in Table 1 according to (affective) input and intended use. 

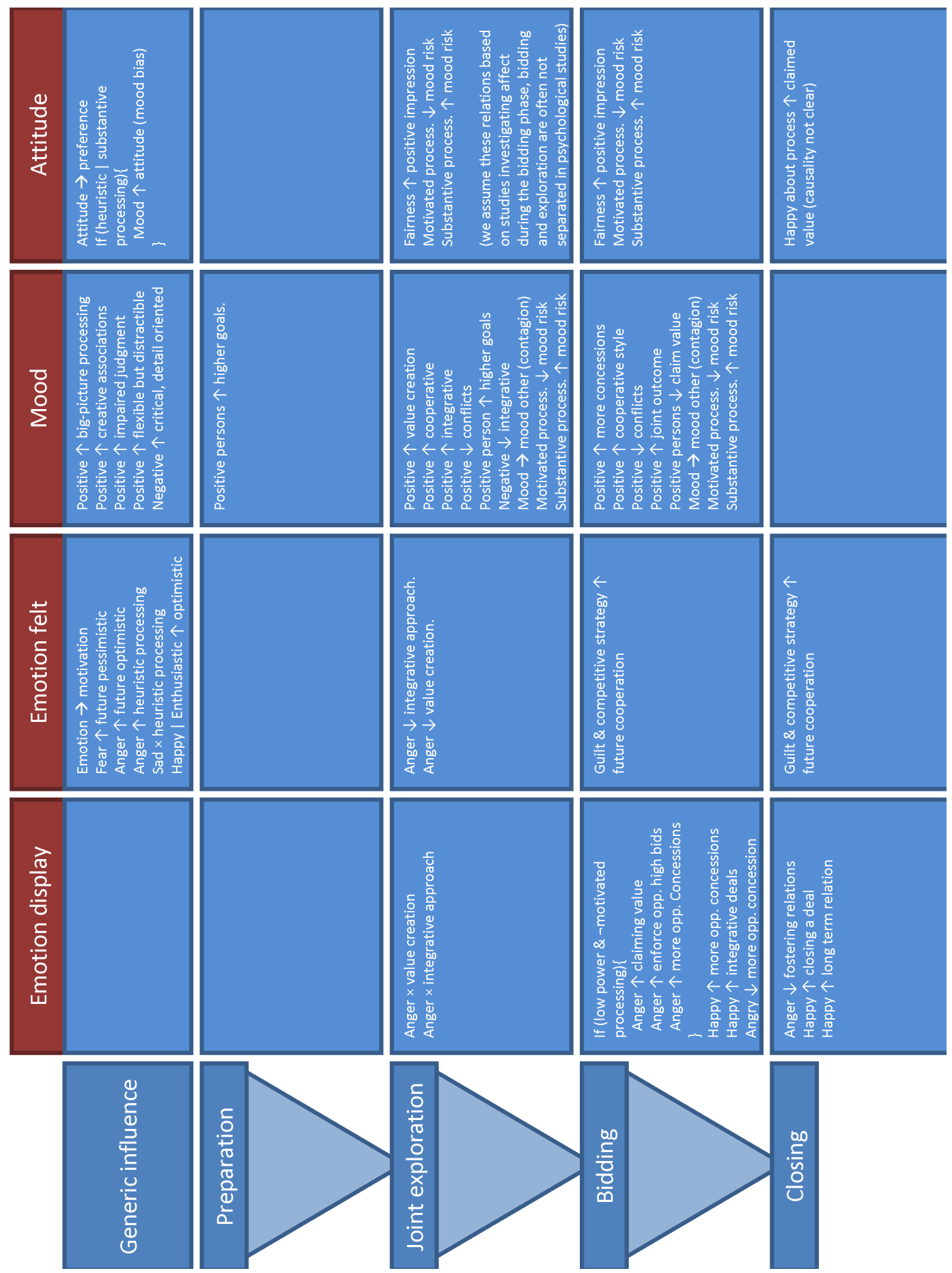

Figure 2. Overview of affective influences on negotiation. The first row summarizes generic influences. Subsequent rows summarize influences per negotiation phase. Signs mean the following: ' $\uparrow$ ' denotes a positive relation, ' $x$ ' denotes no relation, ' $l$ ' denotes a negative relation, ' $\rightarrow$ ' means 'influences' in a more generic sense. See the sections on the relations between affect and cognition/negotiation for further details. 


\section{Affective computing techniques for negotiation support: state of the art.}

The aim for this section is to discuss to what extent the ideas developed in the previous section on affective negotiation support systems are feasible in the short run. We will focus on what can be done now and in the near future given the current state of affective computing. We discuss the state of the art of current affective computing techniques including the following topics:

- emotion measurement: these techniques are needed to capture the emotion, emotion expression and mood of the negotiator as well as to capture affective preferences about options and issues.

- emotion modeling and expression: these techniques are needed to develop affective characters for a virtual scenario training function, and to develop models of human negotiators that include their conflict style, personality and affective reactions to events.

- emotion effects on reasoning: these techniques are needed to realize affective advice generated by the NSS based on known relations between affect and cognition/negotiation, as well as to model characters in interactive training scenarios.

Obviously, the breadth of our topic does not allow us to go deeply into individual studies. Our main aim is to give an overview of the main achievements as well as the open problems in those fields relevant for the affective NSS functions described in the previous section. By doing so we estimate the feasibility of the different functions affect could play in such systems.

We first turn to emotion measurement. Affective user feedback can be divided into two categories: explicit and implicit. Implicit methods sense the behavior of the user (face, body, heart rate, mousemovement, etc.) and deduce an emotion. Explicit methods ask the user to input affective feedback directly.

\subsection{Implicit measurement.}

A large body of research exists on implicit methods to automatically recognize human emotion in a wide variety of modalities [38, 40, 68, 118, 120]. These models typically try to affectively label facial expressions, sounds, gestures and physiological sig- nals such as palmer sweat, heart rate, blood pressure, but also websites and other forms of written texts [94]. The main idea is to extract affectively relevant features from a signal such as an image, movie, or sound. Combinations of features together correlate with particular affective labels such as happy or sad (often as indicated by human subjects analyzing the same signals). Newer research tries to not only extract static features (such as the mouth having a certain angle) but also dynamic features, i.e., movement. These more detailed analyses are needed to differentiate between fake and genuine emotions, a currently unresolved issue in affect recognition. This branch of research is strongly related to signal processing, pattern recognition and machine learning: try to identify relevant features, build a predictive model based on those features and use the model to label the signal. An advantage of using implicit measurement (as compared to explicit measurement) is that the user cannot easily deceive the system (how to fake a heart rate and skin conductance); the measured emotion is probably genuine. In laboratory settings these techniques work quite well, but in settings where a combination of real-life (introducing many noise factors) and real-time usage is needed, use of these techniques is limited [117]. For example, emotional expression recognition is sensitive to the angle of the face with respect to the camera as well facial hair and accessories such as glasses. Emotion recognition from sound works relatively well, but not in noisy environments. A promising area is the recognition of emotion from multiple modalities. Such techniques are currently being investigated in laboratory settings [40]. Emotion recognition based on physiological measures is promising, but still needs to be investigated further in uncontrolled environments that can include many noise introducing factors [83, 92]. Furthermore, many implicit measurement techniques do not interpret the affective signal in the current context of the user. Even if these techniques would work well-enough to be used in a real life setting, these techniques require additional devices such as cameras, high quality microphones, skin conductance measurement and heart rate sensors. It is questionable if negotiators would accept such a high level of intrusion in the negotiation process; in particular if novice negotiators are to be using the NSS (imagine buying a car and asking permission for using a video camera to scan the face of the car salesman). As a result, we anticipate that the use of image and sound-based affect recognition will be limited to negotiation training, private use of an NSS, or settings in which the negotiation takes place at a table in a private room (e.g., face-to-face 
dyadic negotiations). These settings are similar to lab settings in that they have little noise and potentially high sensor availability (via the user's laptop or pc). The detection of arousal through skin conductance and heart-rate signals might be an exception to this as such sensors can be placed on the user relatively unobtrusive and invisible. Advances in wearable sensors [34] could soon enable unobtrusive collection of physiological and behavioral data for emotion recognition, especially when contextual information and other sources such as speech are taken into account [148]. During a negotiation, such sensors can be easily and invisibly attached to a user (e.g., using a wrist watch), and especially for negotiations that have a "sitting" setting, the amount of noise is probably comparable to a lab setting.

To conclude, in the near future automatic affect recognition techniques can be used for affective NSS functions involved in detecting emotion expression, as long as the negotiation setting allows (practically and ethically) the use of multiple sensor modalities, and it does not matter if the emotion is genuine (i.e., faking is not a problem). These functions are $1 \mathrm{~b}$ and 14. Both relate to detecting expressed emotions in different phases and making the user aware of the influences and possible meaning of these expressed emotions. Those functions that need the felt emotion of the negotiator, 1a and 9, focus on fear, enthusiasm and anger detection. High arousal is an important part of these three emotions. Arousal detection can benefit from the use of wearable sensors, as arousal detection from skin conductance and heart rate is relatively accurate, especially in negotiation settings that resemble lab settings as mentioned above. Those functions that need to detect mood from persons are at this point difficult to support with automatic affect recognition as this field, up until now, entirely focuses on human emotion detection [153]. These functions will be discussed on the next section on explicit measurement.

\subsection{Explicit measurement.}

Several approaches exist towards explicit emotion feedback. Some of these ask a user to input discrete (categorical) emotions with or without intensity [43, 77, 133]. The benefit is that discrete emotions are easy to interpret by the user giving the feedback and the person or system interpreting the feedback. The drawback is that mixed emotions are difficult to express as there is no logical "emotional continuum" between categories. This also makes computing with them, e.g., for affective preferences, more difficult. Other approaches are able to, in principle, extract detailed affective information in a non-invasive manner but involve the use of human observers to evaluate the feedback and are more focused on measuring human emotion during the process of product development $[41,90]$. Such approaches give detailed affective feedback but are not suitable for online affect measurement: i.e., affect measurement aimed at getting real-time affective feedback in a format that is usable by a computer system. Several methods exist that are based on the Self-Assessment Manikins (SAM) [14]. Key in these methods is the measurement of emotion dimensions (pleasure, arousal and dominance) directly and separately. For each dimension the user selects a picture from a set of pictures showing emotional faces that express different intensities for that dimension. Although the SAM method is by now well-validated, a potential unresolved limitation is that users must understand the three emotion dimensions before they can use the method. A second drawback is that the method takes up a considerable amount of screen space in an actual interface. Current research focuses on how to embed SAM-based devices in a standard interface and how to ensure that the data produced is machine interpretable, valid and reliable [19]. In general, all approaches have a fundamental tradeoff between precision and ease of use [77]. This means that the more detailed the feedback, the more effort involved for the user and therefore the less likely users are to adopt the method as a common way of entering affective feedback. Furthermore, a user can easily deceive the system. The positive side of the story is that these explicit methods do produce affective feedback that relates to the actually felt emotion, as the user is simply asked for it and there is little interpretation involved. As explicit measures are easy to embed in an NSS (e.g., a mobile NSS), we anticipate that these techniques are usable now and in the near future. In principle explicit techniques can be used to measure emotion, emotion of the opponent, mood and affective attitude. This data can then be used to inform the NSS about the emotion and mood of the user as well as about affective preferences. However, measuring ones own emotion with an explicit device may be cumbersome as the duration of an emotion is short and an emotion is usually intense. It might be difficult to ask a user to give feedback (and translate the emotion to behavior controlling an on screen component) during that emotive period. No studies exist testing the reliability and validity of explicit feedback in such a usage scenario. 
For an NSS, there are 5 different ways of affect measurement with explicit devices: current emotion, past emotion, mood, attitude, and emotion of opponent. We anticipate that explicit devices are useful for those functions that involve mood detection, attitude detection (see Table 1), as well as "detection" of the emotion of the opponent. Measuring mood and attitude is what explicit measurement traditionally has been developed for (e.g., SAM for affective content of pictures, text, movies, and affect questionnaires for mood). An open question is still how to digitize explicit feedback so that it is embeddable in an interface as a small component that gives valid and reliable data for mood and attitude. Recent studies indicate that for attitude (and feelings resulting as a response to a product) this is possible $[19,44]$. This means that detecting affective preferences (function 8 ) is within current reach using explicit affective feedback. Digital explicit measurement tools have not yet been experimentally validated for mood and emotion of others. Although there is no reason to assume this is not possible (in essence an explicit feedback device is a digitized version of a paper affect questionnaire) this has to be shown experimentally. With respect to felt emotions (functions 1a and 9) explicit measurement has not yet been shown to be applicable if the emotion is a short period, is intense and is measured in the moment.

\subsection{Emotion modeling and expression.}

A large part of the affective computing research community is involved in computational modeling of causal factors of emotion in order to use these models in human-computer and human-robot interaction (see, e.g., $[11,16,57,75,115]$ for overviews). Two aspects play a key role: modeling the emotion elicitation and modeling the emotion expression. One often does not go without the other (how to express an emotion without having a model that generates one, and why generate one if you don't express it). Important examples of these approaches are Kismet the emotional robot [17], companion robots such as the Aibo, the iCat, the Huggable and Paro, see [21, 57] for reviews, and a large number of emotional (sometimes called social) agents (avatars) used for tutoring systems (e.g.,[66, 127]) and virtual reality training $[29,49,130]$. Such agents have also been proposed in the context of negotiation training [35, 126]. Early research was primarily aimed at exploring the possibility of creating such affective agents, with the underlying assumption that affective agents are more believable than non-affective agents. Later research is more focused on measuring the effects on users of embedding such agents in particular domains (gaming, training, tutoring) and the effects on users of social and companion robots. Furthermore, there is a strong body of research on how to define and evaluate the affective behavior of such agents [28, 87], and major steps have been taken in the recent past with regards to solid specification of different layers of complexity of the affective behavior of the agent. The techniques to simulate affective characters are approaching commercial applicability. Several open issues include how to render subtle expressions such as small changes in body posture and facial expressions as well as how to simulate mixed emotions. Recent advances have been made into this direction too, enabling the mixture of different emotions (e.g., happiness and sadness) as well as mixing emotion expression across modalities such as gestures and faces [70, 104].

With respect to developing an affective NSS, we anticipate that the modeling and expression of emotion for negotiating agents is within reach (part of function 29). A point of attention is the believability of virtual reality scenarios in the negotiation domain. With believability we refer to objective believability, as in, the content of the scenario, as well as subjective believability, as in, a VR scenario perceived by negotiators. A second point of attention is the dynamical aspects of the scenario including automatic generation of variations based on events and user interaction and automatic explanation of the virtual character's behavior. These issues have not been solved yet, but currently there is quite some research effort into interactive storytelling, mixing user interaction and storyline (plot) into one consistent whole [30], as well as belief-desire-intention-based explanation techniques for virtual agents [36, 69]. As such, we consider the state of the art sufficient to expect plausible, rich, interactive and dynamically changing negotiation scenarios to be a possibility in the near future.

\subsection{Modeling emotion effects on cognition.}

A smaller part of the affective computing community is explicitly concerned with modeling the effects of emotion on reasoning and cognition. These include affective influences on cognition [22, 25, 62, 76, 101, 149 ], formal modeling of cognitive appraisal theory [20, 65, 103, 108], integrating emotional states in agent reasoning $[32,108,141]$ and models of emer- 
gent emotions, such as emerging from the interaction between a simple adaptive agent and its environment $[25,89,136,149]$. These techniques are less relevant for the purpose of developing simple characters that react to their environment in an affective way, or for measuring human emotions. However, these techniques are relevant for modeling the user, in particular the relation between affect and cognition / negotiation. If a system is to help a user cope with particular emotions during a negotiation, then ideally, the system should understand what different emotions do to the behavior of the user. This means the system must have knowledge about, for instance, the influence of affect on decision making. Although many of the studies cited above are implemented models and based on insights from the affect-cognition literature, they are experimental. This means that the behavior generated by the models (simulating affective influences on cognition) is still under evaluation with respect to what is found in studies on human behavior. In fact, the behavior of many of the models cited above has not been evaluated extensively with regards to the affect-cognition literature.

The extent to which an NSS will be able to use affect-cognition relations in the short run is probably limited to contextual tips to the user. By this we mean that the NSS could make the negotiator aware of certain relations between affect and negotiation when these are appropriate. Consider, for example, the functions relating mood to negotiation process (Table 1). If the user is in a measured negative mood, and doing the joint exploration phase, the NSS can alert the user to take into account the fact that he/she will be biased towards negative associations and is not in a creative mood. A formal model of the influences of mood on cognition (e.g., based on Figure 2) could be the basis for such contextual tips.

\subsection{Changing user affect}

Changing human affect on purpose (e.g., for experimental purposes) is also know as affect induction. In affect induction, subjects are typically presented with pictures or videos with the desired affective content. Another method is to give small presents (induce positive affect) or let subjects wait longer before an experiment than they expected (induce negative affect). The idea of affect induction is usually that it results in an unconscious mood change. In affective computing, not many approaches exist that target affect induction. A seminal experiment was done in [134], in which the user was frustrated on purpose by introducing an artificial delay in a computer game's response to user input. Other work relates to the influence of affective expression of agents on users. For example the work in [15] shows that empathic expression by artificial agents increases perceived caring and felt support in human subjects. There is more work like this that focuses on detecting the effects of affective agents (usually in a tutoring setting), however, work explicitly trying to influence user mood in a particular direction using a computer interface is to our knowledge scarce.

However, for an affective NSS this is not necessarily a problem, as classical affect induction techniques can be used for function 13 that needs to help the user get into a different mood for a particular phase in the negotiation process. The other affect changing functions simply operate as reminders to the user to change his/her expression $(1 b, 15,25)$ or attempt to cope with the user's mood by changing the negotiation process (breaks, structuring the bidding, suggesting training, functions $3,5,7,9,20,23$ ) and thus implicitly try to change negotiator affect.

\subsection{Summary}

Emotion and mood measurement via implicit measures are applicable in training situations, private use, or negotiation settings that mimic lab settings (low-noise, availability of sensors), with the exception of heart-rate and sweat levels that get translated to the negotiators level of arousal (stress). Explicit measurements are useful and in the near future good enough to be used in an NSS for mood and attitude measurement. Emotion modeling and expression is currently in such an advanced state that prototype systems of simulated negotiation agents in virtual scenarios can be developed. A possible issue is the plausibility of the virtual scenario itself, as the basic techniques for developing such scenarios (interactive storytelling and explainable agents) is still heavily being researched. Complex (generative) models of emotion effects on cognition are too experimental to use in an NSS, at least for the time being. However, simple rule-based systems could be used to give contextual tips to the user about his/her current emotion and mood and the influences this might have on the course of the negotiation. The issue of changing user affect is unresolved, but most of the functions that try to influence user affect in fact do so through changing the negotiation process (e.g., propose breaks), or reminding the user to show a particular emotional expression. 


\section{Conclusion}

In this article we have argued in a systematic way for the addition of affect-related support in negotiation support systems (NSS). Affect and negotiation are essential elements in our human society. Based on our review of available literature on the relation between affect and cognition/negotiation, we have extracted potential functions an NSS could provide to help negotiators cope with, and strategically use affect during the negotiation process. We call such systems affective negotiation support systems. Such systems provide human-affect related functionality. For example, an affective NSS helps negotiators to be aware of their own emotion and mood and their effects on the negotiation process. Further, an affective NSS gives tips about how to use emotion and mood to favor the right negotiation setting, both in cooperative as well as competitive stages of the negotiation. As we believe that an affective NSS will only provide additional value compared to other negotiation support systems if the functionality is thoroughly based on what is known in the literature on affect and cognition and affect and negotiation, we have provided a structured overview of these findings. We have used this overview to propose different functional requirements for an Affective NSS. Subsequently, we have evaluated the technical feasibility of these functions by linking these to the current state of the art in affective computing. Our analysis leads us to believe that affective negotiation systems are very well realizable in the short term (4 years).

The type of Affective Negotiation Support System we envision is an ambient intelligent device. The Affective NSS runs on a mobile or portable device. It uses low-invasive emotion measurement technology [150] to assess the user's emotional state. Artificial intelligence and user-modeling techniques proactively assist during the negotiation. Such systems will obviously not be "magical devices" able to manipulate any situation into a winning one. Nonetheless, we feel that these systems can help novice negotiators to better prepare for the negotiation and be aware of the potential and pitfalls of emotion, mood and attitudes during a negotiation, as well as provide useful reminders to more experienced negotiators.

\section{Acknowledgments}

We would like to thank 4 anonymous reviewers for their constructive comments, and in particular $\mathrm{Na}$ - tividad Martinez Madrid for her very constructive feedback. This research is supported by the Dutch Technology Foundation STW, applied science division of NWO and the Technology Program of the Ministry of Economic Affairs. It is part of the Pocket Negotiator project with grant number VIVI-project 08075. John-Jules Meyer is partly supported by the Turing Institute Almere.

\section{References}

[1] Aarts, E. and B. de Ruyter, New research perspectives on Ambient Intelligence. Journal of Ambient Intelligence and Smart Environments, 1(1): 5-14, 2009.

[2] Adler, R.S., B. Rosen, and E.M. Silverstein, Emotions in Negotiation: How to Manage Fear and Anger. Negotiation Journal, 14(2): 161-179, 1998.

[3] Anderson, C. and L.L. Thompson, Affect from the top down: How powerful individuals' positive affect shapes negotiations. Organizational Behavior and Human Decision Processes, 95(2): 125-139, 2004.

[4] Ashby, F.G., A.M. Isen, and A.U. Turken, A Neuropsychological Theory of Positive Affect and Its Influence on Cognition. Psychological Review, 106(3): 529-550, 1999.

[5] Augusto, J.C. and H. Aghajan, Editorial: Inaugural issue. Journal of Ambient Intelligence and Smart Environments, 1(1): 1-4, 2009.

[6] Baron, R.A., Environmentally Induced Positive Affect: Its Impact on Self-Efficacy, Task Performance, Negotiation, and Conflict. Journal of Applied Social Psychology, 20(5): 368384, 1990.

[7] Barry, B. and R.L. Oliver, Affect in Dyadic Negotiation: A Model and Propositions. Organizational Behavior and $\mathrm{Hu}$ man Decision Processes, 67(2): 127-143, 1996.

[8] Barsade, S.G., The Ripple Effect: Emotional Contagion and Its Influence on Group Behavior. Administrative Science Quarterly, 47(4): 644-675, 2002.

[9] Beest, I.V., G.A. Van Kleef, and E.V. Dijk, Get angry, get out: The interpersonal effects of anger communication in multiparty negotiation. Journal of Experimental Social Psychology, 44(4): 993-1002, 2008.

[10] Bellucci, E. and J. Zeleznikow, Developing Negotiation Decision Support Systems that Support Mediators: A Case Study of the Family_Winner System. Artificial Intelligence and Law, 13(2): 233-271, 2005.

[11] Bickmore, T.W. and R.W. Picard, Establishing and maintaining long-term human-computer relationships. ACM Trans. Comput.-Hum. Interact., 12(2): 293-327, 2005.

[12] Bodenhausen, G.V., L.A. Sheppard, and G.P. Kramer, Negative affect and social judgment: The differential impact of anger and sadness. European Journal of Social Psychology, 24(1): 45-62, 1994.

[13] Bosse, T. and C.M. Jonker, Human vs. Computer Behaviour in Multi-Issue Negotiation., In T. Ito, et al., editors, Proceedings of the First International Workshop on Rational, Robust, and Secure Negotiations in Multi-Agent Systems. pages 1025. 2005.

[14] Bradley, M.M. and P.J. Lang, Measuring emotion: the SelfAssessment Manikin and the Semantic Differential. Journal of Behav Ther Exp Psychiatry, 25: 49-59, 1994.

[15] Brave, S., C. Nass, and K. Hutchinson, Computers that care: investigating the effects of orientation of emotion exhibited 
by an embodied computer agent. International Journal of Human-Computer Studies, 62(2): 161-178, 2005.

[16] Breazeal, C., Emotion and sociable humanoid robots. International Journal of Human-Computer Studies, 59(1-2): 119155, 2003.

[17] Breazeal, C. and B. Scassellati, Infant-like Social Interactions between a Robot and a Human Caregiver. Adaptive Behavior, 8(1): 49-74, 2000.

[18] Brinkman, W.-P., et al., Getting a Grip on Emotions in Negotiations: the Possibilities of ICT, In Human Aspects in Ambient Intelligence. 2009.

[19] Broekens, J. and W.-P. Brinkman, AffectButton: Towards a Standard for Dynamic Affective User Feedback, In ACII 2009. IEEE, 2009.

[20] Broekens, J., D. DeGroot, and W.A. Kosters, Formal models of appraisal: Theory, specification, and computational model. Cognitive Systems Research, 9(3): 173-197, 2008.

[21] Broekens, J., M. Heerink, and H. Rosendal, Assistive social robots in elderly care: a review. Gerontechnology, 8(2): 94103, 2009.

[22] Broekens, J., W.A. Kosters, and F.J. Verbeek, Affect, Anticipation, and Adaptation: Affect-Controlled Selection of Anticipatory Simulation in Artificial Adaptive Agents. Adaptive Behavior, 15(4): 397-422, 2007.

[23] Butt, A.N. and J.N. Choi, The effects of cognitive appraisal and emotion on social motive and nagotiation behavior: the critical role of agency of negotiator emotion. Human Performance, 19(4): 305-325, 2006.

[24] Büttner, R., The State of the Art in Automated Negotiation Models of the Behavior and Information Perspective. International Transactions on Systems Science and Applications, 1(4): 351-356, 2006

[25] Canamero, D., Designing Emotions for Activity Selection. 2000, University of Aarhus.

[26] Carbonneau, R., G.E. Kersten, and R. Vahidov, Predicting opponent's moves in electronic negotiations using neural networks. Expert Systems with Applications, 34(2): 12661273, 2008.

[27] Carnevale, P.J.D. and A.M. Isen, The influence of positive affect and visual access on the discovery of integrative solutions in bilateral negotiation. Organizational Behavior and Human Decision Processes, 37(1): 1-13, 1986.

[28] Carolis, B.d., et al., APML, a Mark-up Language for Believable Behavior Generation, In H. Prendinger and M. Ishizuka, editors, Life-like characters: tools, affective functions, and applications. pages 65-85. Springer, 2004.

[29] Cassell, J., et al., Animated conversation: rule-based generation of facial expression, gesture \& spoken intonation for multiple conversational agents, In Proceedings of the 21st annual conference on Computer graphics and interactive techniques. ACM, 1994.

[30] Cavazza, M., F. Charles, and S.J. Mead, Character-Based Interactive Storytelling. IEEE Intelligent Systems, 17(4): 1724, 2002.

[31] Chen, E., R. Vahidov, and G.E. Kersten, Agent-supported negotiations in the e-marketplace. International Journal of Electronic Business 3(1): 28-49, 2005.

[32] Coddington, A.M. and M. Luck, Towards motivation-based plan evaluation, In I. Russel and S. Haller, editors, Sixteenth International FLAIRS Conference. pages 298-302. 2003.

[33] Coehoorn, R.M. and N.R. Jennings, Learning on opponent's preferences to make effective multi-issue negotiation tradeoffs, In Proceedings of the 6th international conference on Electronic commerce. ACM, 2004.

[34] Cook, D.J. and W. Song, Ambient intelligence and wearable computing: Sensors on the body, in the home, and beyond.
Journal of Ambient Intelligence and Smart Environments, 1(2): 83-86, 2009.

[35] Core, M., et al., Teaching Negotiation Skills through Practice and Reflection with Virtual Humans. SIMULATION, 82(11): 685-701, 2006.

[36] Core, M.G., et al., Building explainable artificial intelligence systems, In Proceedings of the 18th Conference on Innovative Applications of Artificial Intelligence. 2006.

[37] Cowie, R. and R.R. Cornelius, Describing the emotional states that are expressed in speech. Speech Communication, 40(1-2): 5-32, 2003.

[38] Cowie, R., et al., Emotion recognition in human-computer interaction. Signal Processing Magazine, IEEE, 18(1): 32-80, 2001.

[39] Damasio, A.R., Descartes' Error: emotion reason and the human brain. Penguin Putnam, 1996.

[40] Datcu, D., Multimodal Recognition of Emotions, in ManMachine Interaction. 2009, TU Delft.

[41] de Lera, E. and M. Garreta-Domingo, Ten Emotion Heuristics: Guidelines for Assessing the User's Affective Dimension Easily and Cost-Effectively, In Emotions in HCI workshop, British HCI 2007. 2007.

[42] Der Foo, M., et al., Emotional intelligence and negotiation: The tension between creating and claiming value. International Journal of Conflict Management, 15(4): 411-429, 2004.

[43] Desmet, P., Designing Emotions. Industrial Design. Delft University of Technology: Delft, The Netherlands, 2002.

[44] Desmet, P., Measuring emotion: development and application of an instrument to measure emotional responses to products, In Funology: from usability to enjoyment. pages 111-123. Kluwer Academic Publishers, 2004.

[45] Dijk, E.v., et al., A Social Functional Approach to Emotions in Bargaining: When Communicating Anger Pays and When it Backfires. Journal of Personality and Social Psychology, 94: 600-614, 2008.

[46] Dreisbach, G. and K. Goschke, How positive affect modulates cognitive control: Reduced perseveration at the cost of increased distractibility. Journal of Experimental Psychology: Learning, Memory, and Cognition, 30(2): 343-353, 2004.

[47] Druckman, D. and M. Olekalns, Emotions in negotiation. Group Decision and Negotiation, 17(1): 1-11, 2008.

[48] Ekman, P. and W. Friesen, Unmasking the face: A guide to recognizing emotions from facial expressions. Cambridge, MA: Malor Books, 2003.

[49] Elliott, C., J. Rickel, and J. Lester, Lifelike pedagogical agents and affective computing: an exploratory synthesis, In M. Woolridge and M. Veloso, editors, Artificial Intelligence Today. pages 195-212. Springer, Berlin, 1999.

[50] Ellsworth, P.C. and K.R. Scherer, Appraisal processes in emotion, In R.J. Davidson, Goldsmith, H.H. and Scherer, K.R., editor Handbook of the affective sciences. pages 572595. Oxford University Press, 2003.

[51] Eysenck, M.W., Psychology: An International Perspective. Psychology Press: East Sussex, 2004.

[52] Faratin, P., C. Sierra, and N.R. Jennings, Negotiation decision functions for autonomous agents. Robotics and Autonomous Systems, 24: 159-182, 1998.

[53] Fatima, S., M. Wooldridge, and N.R. Jennings, An analysis of feasible solutions for multi-issue negotiation involving nonlinear utility functions, In Proceedings of The 8th International Conference on Autonomous Agents and Multiagent Systems - Volume 2. International Foundation for Autonomous Agents and Multiagent Systems, 2009. 
[54] Fiedler, K. and H. Bless, The formation of beliefs at the interface of affective and cognitive processes, In N.H. Frijda, A.S.R. Manstead, and S. Bem, editors, Emotions and beliefs. pages 144-170. Cambridge University Press, 2000.

[55] Fisher, R., W. Ury, and B. Patton, Getting to yes: negotiating agreement without giving in. Houghton Mifflin Harcourt, 1991.

[56] Folkman, S. and R.S. Lazarus, Coping and emotion, In N.L. Stein, B. Leventhal, and T. Trabasso, editors, Psychological and Biological Approaches to Emotion. pages 313-332. Lawrence Erlbaum, 1990.

[57] Fong, T., I. Nourbakhsh, and K. Dautenhahn, A survey of socially interactive robots. Robotics and Autonomous Systems, 42(3-4): 143-166, 2003.

[58] Forgas, J.P., Feeling is believing? The role of processing strategies in mediating affective influences in beliefs, In N.H Frijda, A.S.R. Manstead, and S. Bem, editors, Emotions and Beliefs. pages 108-143. Cambridge University Press, 2000.

[59] Frijda, N.H., The Psychologists' Point of View, In M. Lewis, J.M. Haviland-Jones, and L.F. Barrett, editors, Handbook of emotions. pages 68-87. Guilford Press, 2008.

[60] Frijda, N.H., A.S.R. Manstead, and S. Bem, eds. Emotions and Beliefs: How Feelings Influence Thoughts. 2000, Cambridge University Press.

[61] Frijda, N.H. and B. Mesquita, Beliefs through emotions, In N.H. Frijda, A.S.R. Manstead, and S. Bem, editors, Emotions and Beliefs: How Feelings Influence Thoughts. pages 45-77. Cambridge University Press, 2000.

[62] Gadanho, S.C., Learning behavior-selection by emotions and cognition in a multi-goal robot task. J. Mach. Learn. Res., 4: 385-412, 2003.

[63] Gasper, K. and G.L. Clore, Attending to the Big Picture: Mood and Global Versus Local Processing of Visual Information. Psychological Science, 13(1): 34-40, 2002.

[64] George, J.M., G.R. Jones, and J.A. Gonzalez, The Role of Affect in Cross-Cultural Negotiations. Journal of International Business Studies, 29(4): 749-772, 1998.

[65] Gmytrasiewicz, P.J. and C.L. Lisetti, Using decision theory to formalize emotions in multi-agent systems, In Proceedings of the Fourth International Conference on MultiAgent Systems. pages 391-392. 2000.

[66] Graesser, A.C., et al., AutoTutor: an intelligent tutoring system with mixed-initiative dialogue. Education, IEEE Transactions on, 48(4): 612-618, 2005.

[67] Gratch, J., S. Marsella, and P. Petta, Modeling the cognitive antecedents and consequences of emotion. Cognitive Systems Research, 10(1): 1-5, 2009.

[68] Hanjalic, A. and X. Li-Qun, Affective video content representation and modeling. Multimedia, IEEE Transactions on, 7(1): 143-154, 2005.

[69] Harbers, M., K.v.d. Bosch, and J.-J. Meyer, A methodology for developing self-explaining agents for virtual training, In Proceedings of The 8th International Conference on Autonomous Agents and Multiagent Systems - Volume 2. International Foundation for Autonomous Agents and Multiagent Systems, 2009

[70] Hartmann, B., M. Mancini, and C. Pelachaud, Implementing Expressive Gesture Synthesis for Embodied Conversational Agents, In Gesture in Human-Computer Interaction and Simulation. pages 188-199. 2006.

[71] Hegtvedt, K.A. and C. Killian, Fairness and Emotions: Reactions to the Process and Outcomes of Negotiations. Social Forces, 78(1): 269-302, 1999.

[72] Hindriks, K. and D. Tykhonov, Opponent modelling in automated multi-issue negotiation using Bayesian learning, In Proceedings of the 7th international joint conference on
Autonomous agents and multiagent systems - Volume 1. International Foundation for Autonomous Agents and Multiagent Systems, 2008.

[73] Hindriks, K.V. and C.M. Jonker, Creating Human-Machine Synergy in Negotiation Support Systems: Towards the Pocket Negotiator, In W.-P. Brinkman, editor Proc. of the 1st Int. Working Conference on Human Factors and Computational Models in Negotiation, HuCom 2008. pages 47-54. 2008.

[74] Hofstede, G. and G.J. Hofstede, Cultures and Organizations: Software of the Mind. McGraw-Hill, 2005.

[75] Hudlicka, E., To feel or not to feel: The role of affect in human-computer interaction. International Journal of $\mathrm{Hu}$ man-Computer Studies, 59(1-2): 1-32, 2003.

[76] Hudlicka, E., Modeling the Mechanisms of Emotion Effects on Cognition, In Proceedings of the AAAI Fall Symposium on Biologically Inspired Cognitive Architectures. pages 8286. AAAI Press, 2008.

[77] Isomursu, M., et al., Experimental evaluation of five methods for collecting emotions in field settings with mobile applications. International Journal of Human-Computer Studies, 65(4): 404-418, 2007.

[78] Johnson, N.A., R.B. Cooper, and W.W. Chin, Anger and flaming in computer-mediated negotiation among strangers. Decision Support Systems, 46(3): 660-672, 2009.

[79] Jonker, C.M., V. Robu, and J. Treur, An agent architecture for multi-attribute negotiation using incomplete preference information Autonomous Agents and Multi-Agent Systems, 15(2): 32, 2007.

[80] Jonker, C.M. and J. Treur, An Agent Architecture for MultiAttribute Negotiation, In Nebel, editor Proceedings of the 17th International Joint Conference on AI. pages 1195-1201. 2001.

[81] Kersten, G.E. and G. Lo, Aspire: an integrated negotiation support system and software agents for e-business negotiation. International Journal of Internet and Enterprise Management, 1(3): 293-315, 2003.

[82] Ketelaar, T. and W.T. Au, The effects of feelings of guilt on the behaviour of uncooperative individuals in repeated social bargaining games: An affect-as-information interpretation of the role of emotion in social interaction. . Cognition \& Emotion, 17(3): 429-453, 2003

[83] Kim, K., S. Bang, and S. Kim, Emotion recognition system using short-term monitoring of physiological signals. Medical and Biological Engineering and Computing, 42(3): 419427, 2004.

[84] Kleef, G.A.v., C.K.W. De Dreu, and A.S.R. Manstead, The Interpersonal Effects of Emotions in Negotiations: A Motivated Information Processing Approach. Journal of Personality \& Social Psychology, 87(4): 510-528, 2004.

[85] Kleef, G.A.v., et al., Power and emotion in negotiation: power moderates the interpersonal effects of anger and happiness on concession making. European Journal of Social Psychology, 36(4): 557-581, 2006.

[86] Kopelman, S., A.S. Rosette, and L. Thompson, The three faces of Eve: Strategic displays of positive, negative, and neutral emotions in negotiations. Organizational Behavior and Human Decision Processes, 99(1): 81-101, 2006.

[87] Kopp, S., et al., Towards a Common Framework for Multimodal Generation: The Behavior Markup Language, In Intelligent Virtual Agents. pages 205-217. 2006.

[88] Kraus, S., Strategic Negotiation in Multiagent Environments. MIT Press: Cambridge, MA, 2001.

[89] Lahnstein, M., The emotive episode is a composition of anticipatory and reactive evaluations, In L. Cañamero, editor Agents that want and like: Motivational and emotional roots 
of cognition and action. Papers from the AISB'05 Symposium. pages 62-69. AISB Press, 2005.

[90] Laurans, G. and P.M.A. Desmet, Using self-confrontation to study user experience: A new approach to the dynamic measurement of emotions while interacting with products, In P.M.A. Desmet, M.A. Karlsson, and J.v. Erp, editors, Design \& Emotion 2006. 2006.

[91] LeDoux, J., The Emotional Brain. Simon and Shuster: New York, 1996.

[92] Leon, E., et al., A user-independent real-time emotion recognition system for software agents in domestic environments. Engineering Applications of Artificial Intelligence, 20(3): 337-345, 2007.

[93] Lerner, J.S. and D. Keltner, Beyond valence: Toward a model of emotion-specific influences on judgement and choice. Cognition and Emotion, 14(4): 473-493, 2000.

[94] Leshed, G. and J.J. Kaye, Understanding how bloggers feel: recognizing affect in blog posts, In $\mathrm{CHI}$ '06 extended $a b$ stracts on Human factors in computing systems. pages 10191024. ACM, 2006.

[95] Lewis, M., J.M. Haviland-Jones, and L.F. Barrett, eds. Handbook of Emotions. Third ed. 2008, The Guilford Press.

[96] Li, M., Q.B. Vo, and R. Kowalczyk, Searching for fair joint gains in agent-based negotiation, In Proceedings of The 8th International Conference on Autonomous Agents and Multiagent Systems - Volume 2. pages 1049-1056. International Foundation for Autonomous Agents and Multiagent Systems, 2009.

[97] Lin, R., et al., An Automated Agent for Bilateral Negotiation with Bounded Rational Agents with Incomplete Information, In Proceeding of the 2006 conference on ECAI 2006: 17th European Conference on Artificial Intelligence August 29 -September 1, 2006, Riva del Garda, Italy. pages 270-274. IOS Press, 2006

[98] Lin, R., Y. Oshrat, and S. Kraus, Investigating the benefits of automated negotiations in enhancing people's negotiation skills, In Proceedings of The 8th International Conference on Autonomous Agents and Multiagent Systems - Volume 1. pages 345-352. International Foundation for Autonomous Agents and Multiagent Systems, 2009.

[99] Luecke, R., Harvard business essentials: negotiation. Harvard Business School Press, 2003.

[100] Mackie, D.M. and L.T. Worth, Processing deficits and the mediation of positive affect in persuasion. Journal of Personality and Social Psychology, 57(1): 27-40, 1989.

[101] Marinier Iii, R.P., J.E. Laird, and R.L. Lewis, A computational unification of cognitive behavior and emotion. Cognitive Systems Research, 10(1): 48-69, 2009.

[102] Marsa-Maestre, I., et al., Effective bidding and deal identification for negotiations in highly nonlinear scenarios, In Proceedings of The 8th International Conference on Autonomous Agents and Multiagent Systems - Volume 2. pages 1057-1064. International Foundation for Autonomous Agents and Multiagent Systems, 2009.

[103] Marsella, S.C. and J. Gratch, EMA: A process model of appraisal dynamics. Cognitive Systems Research, 10(1): 7090, 2009.

[104] Martin, J.C., et al., Multimodal Complex Emotions: Gesture Expressivity And Blended Facial Expressions. Special issue of the Journal of Humanoid Robotics 3: 269-291, 2006.

[105] Mastenbroek, W., Negotiating as Emotion Management. Theory Culture Society, 16(4): 49-73, 1999.

[106] Mehrabian, A., Basic Dimensions for a General Psychological Theory. OG\&H Publishers, 1980.
[107] Mehrabian, A. and J.A. Russell, A verbal measure of information rate for studies in environmental psychology. Environment and Behavior, 6: 233-252, 1974.

[108] Meyer, J.-J.C., Reasoning about emotional agents. International Journal of Intelligent Systems, 21(6): 601-619, 2006.

[109] Meyer, T., et al., Logical Foundations of Negotiation: Outcome, Concession, and Adaptation, In Proceedings of AAAI 2004. pages 293-298. 2004.

[110] Mitchell, R.L.C. and L.H. Phillips, The psychological, neurochemical and functional neuroanatomical mediators of the effects of positive and negative mood on executive functions. Neuropsychologia, 45(4): 617-629, 2007.

[111] Oaksford, M., et al., Mood, reasoning, and central executive processes. Journal of Experimental Psychology: Learning, Memory, and Cognition, 22(2): 477-493, 1996.

[112] Oliver, J.R., On Learning Negotiation Strategies by Artificial Adaptive Agents in Environments of Incomplete Information., In Formal Modelling in Electronic Commerce, International Handbooks on Information Systems, Part IV. pages 445-461. 2005

[113] Ortony, A., G.L. Clore, and A. Collins, The Cognitive Structure of Emotions. Cambridge University Press, 1988.

[114] Oshrat, Y., R. Lin, and S. Kraus, Facing the challenge of human-agent negotiations via effective general opponent modeling, In Proceedings of The 8th International Conference on Autonomous Agents and Multiagent Systems - Volume 1. pages 377-384. International Foundation for Autonomous Agents and Multiagent Systems, 2009.

[115] Paiva, A., Affective Interactions: Toward a New Generation of Computer Interfaces?, In Affective Interactions. pages 1-8. 2000.

[116] Panksepp, J., Affective Neuroscience: the foundations of human and animal emotions. Oxford University Press, 1998.

[117] Pantic, M., et al., Human Computing and Machine Understanding of Human Behavior: A Survey, In Artifical Intelligence for Human Computing. pages 47-71. 2007.

[118] Pantic, M. and L.J.M. Rothkrantz, Automatic Analysis of Facial Expressions: The State of the Art. IEEE Trans. Pattern Anal. Mach. Intell., 22(12): 1424-1445, 2000

[119] Phaf, R.H. and M. Rotteveel, Affective modulation of recognition bias. Emotion, 5(3): 309-318, 2005.

[120] Picard, R.W., Affective Computing. MIT Press, 1997.

[121] Picard, R.W., Affective computing: challenges. International Journal of Human-Computer Studies, 59(1-2): 55-64, 2003.

[122] Pietroni, D., et al., Emotions as strategic information: Effects of other's emotional expressions on fixed-pie perception, demands, and integrative behavior in negotiation. Journal of Experimental Social Psychology, 44(6): 1444-1454, 2008.

[123] Pommeranz, A., et al., Design Guidelines for Negotiation Support Systems: An Expert Perspective Using Scenarios, In ECCE 2009. ACM, 2009.

[124] Rahwan, I., L. Sonenberg, and P. McBurney, Bargaining and Argument-based Negotiation: Some Preliminary Comparisons, In I. Rahwan, P. Moraitis, and C. Reed, editors, Argumentation in Multi-Agent Systems. pages 176-191. SpringerVerlag, 2005

[125] Raiffa, H., The Art and Science of Negotiation. Harvard University Press, 1982.

[126] Reilly, W.S. and J. Bates, Natural Negotiation for Believable Agents. 1995.

[127] Rickel, J. and W.L. Johnson, Integrating pedagogical capabilities in a virtual environment agent, In Proceedings of the first international conference on Autonomous agents. ACM, 1997.

[128] Rolls, E.T., Precis of The Brain and Emotion. Behavioral and Brain Sciences, 20: 177-234, 2000. 
[129] Rosenschein, J.S. and G. Zlotkin, Rules of Encounter. MIT Press: Cambridge, MA, 1994.

[130] Rosis, F.d., et al., From Greta's mind to her face: modelling the dynamics of affective states in a conversational embodied agent. International Journal of Human-Computer Studies, 59(1-2): 81-118, 2003.

[131] Russell, J., Core affect and the psychological construction of emotion. Psychological Review, 110(1): 145-172, 2003.

[132] Salacuse, J.W., Ten Ways that Culture Affects Negotiating Style: Some Survey Results. Negotiation Journal, 14(3): 221-240, 1998.

[133] Sánchez, J.A., et al., Conveying Mood and Emotion in Instant Messaging by Using a Two-Dimensional Model for Affective States, In Anais do IHC 2006. pages 66-72. 2008.

[134] Scheirer, J., et al., Frustrating the user on purpose: a step toward building an affective computer. Interacting with Computers, 14(2): 93-118, 2002.

[135] Scherer, K.R., A. Schorr, and T. Johnstone, eds. Appraisal Processes in Emotion: Theory, Methods, Research. 2001, Oxford University Press.

[136] Scheutz, M., Useful Roles of Emotions in Artificial Agents: A Case Study from Artificial Life, In Proceedings of the $A A A I$. pages 42-47. AAAI Press, 2004.

[137]Sebe, N., Multimodal interfaces: Challenges and perspectives. Journal of Ambient Intelligence and Smart Environments, 1(1): 23-30, 2009.

[138] Sinaceur, M. and L.Z. Tiedens, Get mad and get more than even: When and why anger expression is effective in negotiations. Journal of Experimental Social Psychology, 42(3): 314-322, 2006.

[139] Steinel, W., G.A. Van Kleef, and F. Harinck, Are you talking to me?! Separating the people from the problem when expressing emotions in negotiation. Journal of Experimental Social Psychology, 44(2): 362-369, 2008.

[140] Steunebrink, B.R., M. Dastani, and J.-J.C. Meyer, A Logic of Emotions for Intelligent Agents, In Proceedings of the 22th National Conference on Artifical Intelligence (AAAI '07). pages 142-147. AAAI Press, 2007.

[141] Steunebrink, B.R., M. Dastani, and J.-J.C. Meyer, A Formal Model of Emotions: Integrating Qualitative and Quatitative Aspects, In Proceedings of the European Confernce on Artifical Intelligence (ECAI '08). pages 256-260. IOS Press, 2008.

[142] Tamma, V., et al., Ontologies for supporting negotiation in ecommerce. Engineering Applications of Artificial Intelligence, 18(2): 223-236, 2005.

[143] Thompson, L. and J. Nadler, Negotiating via Information Technology: Theory and Application. Journal of Social Issues, 58(1): 109-124, 2002.

[144] Thompson, L.L., The Heart and Mind of the Negotiator. Pearson Prentice Hall: Upper Saddle River, N. J., 2005.

[145] Thompson, L.L., J. Nadler, and P.H. Kim, Some like it hot: The case for the emotional negotiator, In L.L. Thompson, J.M. Levine, and D.M. Messick, editors, Shared cognition in organizations: The management of knowledge. pages 139161. Erlbaum., 1999.

[146] Ursin, H. and H.R. Eriksen, The cognitive activation theory of stress. Psychoneuroendocrinology, 29(5): 567-592, 2004.

[147] Ury, W., The Power of a Positive No: How to Say No and Still Get to Yes. Bantam Books / Random House, 2007.

[148] van den Broek, E.L., et al., Unobtrusive Sensing of Emotions (USE). Journal of Ambient Intelligence and Smart Environments, 1(3): 287-299, 2009.

[149] Velasquez, J., Modeling emotion-based decision making. , In Proceedings of the AAAI Fall Symposium on Emotional and
Intelligent: The Tangled Knot of Cognition. AAAI Press, 1998.

[150] Westerink, J., et al. Emotion measurement platform for daily life situations. In Affective Computing and Intelligent Interaction and Workshops, 2009. ACII 2009. 3rd International Conference on. 2009

[151] Wong, C.-S., K.S. Law, and P.-M. Wong, Development and Validation of a Forced Choice Emotional Intelligence Measure for Chinese Respondents in Hong Kong. Asia Pacific Journal of Management, 21(4): 535-559, 2004.

[152]Zeng, D. and K. Sycara, Bayesian learning in negotiation. Int. J. Hum.-Comput. Stud., 48(1): 125-141, 1998.

[153] Zeng, Z., et al., A Survey of Affect Recognition Methods: Audio, Visual, and Spontaneous Expressions. Pattern Analysis and Machine Intelligence, IEEE Transactions on, 31(1): 39-58, 2009. 